\title{
Attentional tracking and inhibition of return in dynamic displays
}

\author{
HERMANN J. MÜLLER and ADRLAN vON MÜHLENEN \\ Birkbeck College, University of London, London, England
}

\begin{abstract}
Seven experiments were conducted to replicate, and extend, a finding by Tipper, Driver, and Weaver (1991). They reported evidence for dynamic, object-centered inhibition of return (IOR) - that is, coding of inhibition following a peripheral cue in coordinates that move with the previously cued object, providing a dynamic bias against reattending to that object. The present experiments used a variation of Posner and Cohen's (1984) spatial cuing paradigm. Subjects responded manually (simple reaction time) to a luminance increment in one of two peripheral boxes, one of which had previously been cued (brightened). Experiments 1, 2, and 5 replicated the standard (environmental) IOR effect when the display was stationary. IOR was more marked for right-side targets than for left-side targets and tended to be affected by the compatibility between response hand and (cued) target position. However, when the boxes moved around the display center (Experiments 1,2,3,4,6, and 7), contrary to Tipper et al., there was no evidence of dynamic, object-centered IOR. Rather, there was strong evidence of attentive tracking of whatever box happened to move from left to right, irrespective of the direction of its motion (clockwise or counterclockwise) and whether it was more likely to contain the target than the other (rightto-left moving) box. There was a tendency for left-to-right tracking to be more marked with right-hand responses, pointing to the existence of a dynamic stimulus-response compatibility effect. The implications of the present findings for the role of attentive tracking and IOR in dynamic scenes are discussed.
\end{abstract}

Many everyday visual inspection and search tasks involve the serial scrutiny of the environment until a target (e.g., a "fault") is detected. Such everyday tasks are similar to visual search experiments conducted in the psychological laboratory. In the laboratory, subjects typically search for a target object among varying numbers of nontarget objects (the display size) and their reaction times (RTs) to detecting the target are measured. Targets that are difficult to detect give rise to linearly increasing search RT/display size functions. Most recent theories of visual search (e.g., Cave \& Wolfe, 1990; Treisman, 1988; Treisman \& Gelade, 1980 ) take such functions to be indicative of a spatially serial, item-by-item search process involving "focal attention," where the shifts of focal attention may be entirely covert (i.e., not accompanied by overt eye, head, and/or body movements). One question of importance to all theories of visual search ${ }^{1}$ and inspection is: How does the serial scanning mechanism keep track of where focal attention has already been so that it does not unnecessarily return to the same location or object?

This research was supported by SERC Grant GR/H/54966 to H.J.M The authors would like to thank Scott Little and Kate Parmenter for their help with conducting some of the experiments. Many thanks are also extended to A. Kramer, S. Tipper, S. Yantis, and one anonymous reviewer for their helpful comments on a previous draft of this paper, and to R. Klein and D. Watson for stimulating discussions of the nature of IOR. Correspondence concerning this article should be addressed to $\mathrm{H}$. J. Müller, Department of Psychology, Birkbeck College, University of London, Malet Street, London WC1E 7HX, England (e-mail: h.muller@ psyc.bbk.ac.uk).

\section{Inhibition of Return}

Empirical evidence pertinent to this question comes from Posner and Cohen's (1984) inhibition of return (IOR) effect. Posner and Cohen observed that it is "harder" (i.e., it takes more time) to redirect attention to a recently attended location, or to an object at that location, than it is to direct attention to an unattended location. In other words, shortly after having attended to a location or object, there is a momentary bias against reattending to it. This bias, which is manifest with both covert and overt orienting of attention (the latter involving eye movements; Posner, Rafal, Choate, \& Vaughan, 1985), modulates spatial selectivity by favoring novel locations in visual scanning.

Various paradigms have been used to investigate this effect (e.g., Klein, 1988; Posner \& Cohen, 1984). Posner and Cohen (1984) used a spatial cuing paradigm. Subjects fixated at the center of a central box. A trial began with the brightening of the outline of one of the two peripheral boxes (to the left and right) selected at random (the cue). Then a luminance increment target appeared at the center of a box at a variable time (stimulus onset asynchrony, SOA) after the onset of the peripheral cue. The target was most likely to be presented in the central box, but it could also appear on either side. Subjects were instructed to respond to the target as quickly as possible by pressing a response key ("simple RT" procedure). Posner and Cohen found that the peripheral cue produced an RT advantage for targets presented at the cued position within the first $150 \mathrm{msec}$ after cue onset (i.e., the cue summoned attention). This facilitation was then, after about $300 \mathrm{msec}$, replaced by an RT disadvantage for targets on the cued side relative to the un- 
cued side. This inhibition was particularly marked when attention had been summoned to the center by the brightening of the central box (however, note that, according to Maylor \& Hockey, 1985, attention need not be withdrawn for IOR to occur; see also Gibson \& Egeth, 1994a).

However, the IOR effect is obtained only under special conditions. In one of their experiments, Posner and Cohen (1984) used a central (rather than a peripheral) cue to direct attention to the likely (peripheral) target location (the cue was an arrow presented above the central fixation box). The results showed facilitation following the arrow cue, but there was no inhibition following the return of attention to the center (see also Rafal, Calabresi, Brennan, \& Sciolto, 1989). That is, the IOR effect is generally only obtained with peripheral cues. This suggests that IOR is linked to stimulus-driven attention systems, probably located in the midbrain and involved in the programming of saccadic eye movements (see also Posner et al., 1985). The latter is consistent with a recent report by Rafal et al. (1989) that IOR can be obtained with central cues if subjects actively prepare an eye movement to the cued location, which is then canceled.

One further issue concerns whether or not prior orienting of attention to the peripheral cue is a necessary condition for IOR to occur. Posner and Cohen (1984) argued that prior orienting was not necessary. They found that IOR was not reduced when two locations were peripherally cued simultaneously (double cue) relative to when only one location was cued (single cue). Posner and Cohen assumed that two locations cannot be oriented to simultaneously and so concluded that prior orienting was not necessary for IOR to occur. However, Posner and Cohen's critical assumption may be questionable (e.g., Castiello \& Umiltà, 1992; Müller, 1995). Also, contrary to Posner and Cohen, Maylor (1985) did find a decrement in IOR for double-cue trials relative to single-cue trials. Furthermore, she observed that, when subjects tracked a central spot of light that could move unpredictably at the time that a peripheral cue was presented, facilitation for a peripheral target was reduced and there was no IOR. In other words, when performance of a secondary task interfered with orienting to the cue, both facilitation and inhibition were affected. Findings such as these argue that prior orienting is a prerequisite for IOR to occur.

\section{Coordinates of the IOR Effect}

One question of major interest concerns the coordinate (or frame-of-reference) system in which the IOR effect is coded. Maylor and Hockey (1985) attempted to decide whether IOR is coded in "retinal" or "environmental" coordinates. They required their subjects to make a vertical (downward) eye movement after the presentation of a peripheral cue but before the presentation of the target. They reasoned that, if IOR is coded in environmental coordinates, the eye movement should leave targets at the originally stimulated (cued) location most affected. However, if IOR is coded in retinal coordinates, only targets that ap- pear at the retinal location of the cue (i.e., a changed environmental location after the eye movement) ought to be inhibited. Maylor and Hockey's findings were consistent with environmental coding of the IOR effect (in agreement with Posner \& Cohen, 1984).

Tipper, Driver, and Weaver (1991) carried this line of inquiry further. They pointed out that tagging fixed environmental coordinates is not a satisfactory solution to coping with a dynamic visual environment in which objects' locations may continually change (due to their movement). A more satisfactory solution would be an inhibitory tagging mechanism that operates in dynamic, objectcentered coordinates. To investigate object-centered IOR, they adapted Posner and Cohen's (1984) basic paradigm. There were three boxes: a central (fixation) box and two peripheral boxes. The innovation of Tipper et al. was to make the outer boxes move around the center in a clockwise direction. Movement started after the cue-a brief dimming of, say, the left box (cues were spatially uninformative as to the target box). Tipper et al. reported that IOR moved with the cued box. For example, $430 \mathrm{msec}$ after (left) cue onset, the cued box had moved to the upper position and the uncued box to the lower position. RTs at that SOA were slower to targets in the cued box (upper position) than to targets in the uncued box (lower position). Six hundred ninety-five milliseconds after (left) cue onset, the cued box had moved to the right position and the uncued box to the left position. RTs at that SOA were slower to targets in the cued box (right position) than to targets in the uncued box (left position), although the uncued box occupied the physical location of the preceding cue. Tipper et al. took this finding as evidence for dynamic, objectcentered coding of the IOR effect.

The existence of dynamic, object-centered IOR was recently confirmed by Tipper, Weaver, Jerreat, and Burak (1994). Their Experiments 1-3 replicated the basic effect of Tipper et al. (1991). Interestingly, though, Tipper et al. (1994) found no RT difference between the cued box and the uncued box after a $180^{\circ}$ rotation (in contrast to Experiments 2 and 3 of Tipper et al., 1991, which showed no evidence of reduced dynamic, object-centered IOR after semicircular rotations). For example, in their Experiment 3, the starting positions of the boxes varied randomly around the circle (i.e., there were also nonhorizontal alignments), and the rotation could be clockwise or counterclockwise. Inhibition was $-11 \mathrm{msec}$ at $90^{\circ}$ rotation and nonexistent $(+3 \mathrm{msec})$ at $180^{\circ}$ rotation..$^{2}$ Tipper et al. (1994) argued that, with a $180^{\circ}$ rotation, IOR to the environmental location of the cue (e.g., left) is counterbalanced by object-centered IOR to the cued box (right)-the assumption being that environmental IOR and dynamic, object-centered IOR are separable components of the IOR effect.

In their Experiments 4 and 5, Tipper et al. (1994) attempted to dissociate environmental IOR from objectcentered IOR. Displays contained four equidistant (different-colored) boxes and the (clockwise) rotation was $90^{\circ}$. RTs were measured to (1) targets in two uncued boxes 
(that "ahead of" and that "across" the cued box, (2) targets in the box "behind" the cued box (which, after the $90^{\circ}$ rotation, occupied the environmental position of the cue), and (3) targets in the cued box. The "ahead + across box" RTs were compared with the "behind box" and "cued box" RTs to estimate the environmental and object-centered IOR effects. Both were found to be of about $15 \mathrm{msec}$.

In their Experiment 6, Tipper et al. (1994) attempted to show that object-centered IOR is associated only with objects visible at the time of the cue. There were two static boxes and two different-colored boxes that moved. At the time of the cue, the moving boxes could be occluded by the static boxes ("static near" condition) or the static boxes could be occluded by the moving boxes ("moving near" condition). In the "static near" condition, there was inhibition of $-11 \mathrm{msec}$ for the cued ("static") box but no effect for the moving box that was occluded by the cued static box at the time of the cue. In contrast, in the "moving near" condition, there was (significant) inhibition of $-6 \mathrm{msec}$ for both the cued moving box (visible at the time of the cue) and the static box occluded by the cued moving box at the time of the cue.

Evidence for dynamic, object-centered IOR was also reported by Abrams and Dobkin (1994). They found that, after a quarter-circle movement of a peripherally cued box, the latency of saccadic eye movements to that box showed evidence of IOR only if the imperative signal for making the saccade occurred inside the cued box, but not if it occurred in the display center. Abrams and Dobkin concluded that detection of the imperative stimulus in the cued box is affected by dynamic, object-centered IOR but not the eye movement to that box as such. ${ }^{3}$

\section{Overview of the Present Experiments}

The present experiments were designed to reinvestigate the dynamic, object-centered IOR effect, taking the experiments of Tipper et al. (1991) as their starting point. ${ }^{4}$ Since this effect was reliably obtained in previous work (e.g., Abrams \& Dobkin, 1994; Tipper et al., 1991; Tipper et al., 1994), it seemed justifiable to make some modifications to the basic paradigm of Tipper et al. (1991).

One modification concerned the use of short cue-target SOAs and cues that were spatially informative as to the likely target box prior to the center brightening to demonstrate facilitation for the cued box preceding IOR. Tipper et al (1991; Tipper et al., 1994) used only long SOAs and so could not tell whether or not prior orienting of attention to the cued box is a necessary condition for dynamic, objectcentered IOR to occur (see the debate between Posner \& Cohen, 1984, and Maylor, 1985, in relation to environmental IOR). One related question concerned whether the early attentive facilitation would be dynamic (i.e., whether it would move with the cued object) and at what time it would be replaced by dynamic inhibition. To observe facilitation indicative of orienting to cue, the present experiments used short cue-target SOAs, and (in Experiments 2-6) the cue was made spatially informative before the center brightening. To observe dynamic facilitation, the movement of the peripheral boxes started immediately after the offset of the peripheral cue and the onset of the central brightening was delayed.

Furthermore, the present experiments presented a high proportion of central targets to provide an incentive for subjects to maintain eye fixation, and fixation was directly monitored in Experiment 4. Without effective control, it cannot be ruled out that dynamic, object-centered IOR effects are contaminated by eye movements (e.g., a saccade to the left-cued location at some intermediate SOAs would produce an RT disadvantage for targets to the right). Tipper et al. (1991; Tipper et al., 1994) provided no central targets, but Tipper et al. (1994) replicated the dynamic, objectcentered IOR effect in their Experiment 5 in which they monitored eye movements (though only by the experimenter watching the subjects' eyes as they performed the task; see also Abrams \& Dobkin, 1994, who recorded eye movements). Thus, dynamic, object-centered IOR is not an eye-movement artifact. Nevertheless, it seemed preferable in the present experiments to minimize any confounding by eye movements by providing subjects with a strong incentive to maintain fixation (especially in Experiments 2-6 in which the peripheral cues were initially valid).

Note that there were other methodological differences to Tipper et al. (1991), which were deemed to be noncritical for dynamic, object-centered IOR to occur. In particular, the present experiments used brightening (onset) cues rather than dimming (offset) cues (see also Abrams \& Dobkin, 1994), "smooth" motion of the peripheral boxes rather than "jerky" motion, and continuous presentation of the target until response rather than brief presentation. All these changes are justifiable on ecological grounds: onset cues are more powerful in capturing attention than are offset cues (e.g., Jonides \& Yantis, 1988; Yantis, 1993; Yantis \& Jonides, 1984), real-world object motion is continuous, and a critical change in an object's appearance (the target) tends to be visible (and move with the object) for some time.

For the replication to be successful, the present experiments not only should have demonstrated the standard (i.e., environmental) IOR effect with stationary displays (by showing an RT disadvantage to targets on the cued side relative to the uncued side) but also should have demonstrated dynamic, object-centered IOR with moving displays. However, the present study failed to provide any evidence of dynamic, object-centered IOR, although there was consistent evidence of "attentive tracking" of the object that moved from left to right. The experiments to be reported explored the boundary conditions of dynamic, object-centered IOR (i.e., methodological factors that may be important in producing it) as well as the nature of the attentive-tracking effect.

\section{EXPERIMENT 1}

Experiment 1 was designed to replicate and extend the basic findings of Tipper et al. (1991), with several methodological modifications (see below). 


\section{Method}

Subjects. Ten subjects ( 6 males and 4 females, with ages ranging from 18 to 36 years) participated in Experiment 1. Eight had normal vision, and 2 had corrected-to-normal vision. All subjects were right-handed. They were paid $£ 4.00$ per session.

Apparatus. Stimuli were presented on a Tektronix $608 \mathrm{X}-\mathrm{Y}$ monitor with P31 phosphor and driven by an LSI 11/23 computer by way of a CED 502 laboratory interface. Display refreshing and sampling of digital inputs were controlled by Shepherd's (1984) EMDISP software system. The laboratory was dimly illuminated (to eliminate reflections). Stimulus luminance was $0.34 \mathrm{~cd} / \mathrm{m}^{2}$, and screen background luminance was $0.034 \mathrm{~cd} / \mathrm{m}^{2}$. The subjects viewed the screen from a distance of $1 \mathrm{~m}$, with their heads supported by a chinrest.

Procedure. There were two basic conditions, stationary and moving, which were counterbalanced across subjects. Figure 1 illustrates the sequence of events on a trial in the two conditions. At the beginning of each block of trials, a box was displayed in the center of the screen; the subjects initiated a block by pressing a designated key on the hand-held keypad. In addition to the central box, two peripheral boxes then appeared. The sides of each box subtended $0.45^{\circ}$ of visual angle, and their eccentricity was $1.5^{\circ}$ (distance from the midpoint of the screen to the center of a box). (Note that Tipper et al. used a larger eccentricity, $7.2^{\circ}$, but this was experienced as "uncomfortable" by subjects participating in pilot work to Experiment 1.) The two peripheral boxes were arranged such that the left-hand box was rotated $30^{\circ}$ (in polar coordinates) below the horizontal midline (through the center of the central box) and the right-hand box was rotated $30^{\circ}$ above the midline (see Figures $1 \mathrm{~A}$ and $1 \mathrm{~B}$ ). The peripheral boxes maintained these positions for $1,000 \mathrm{msec}$. They then moved clockwise on a circular path into the horizontal positions (on

A)

Static condition

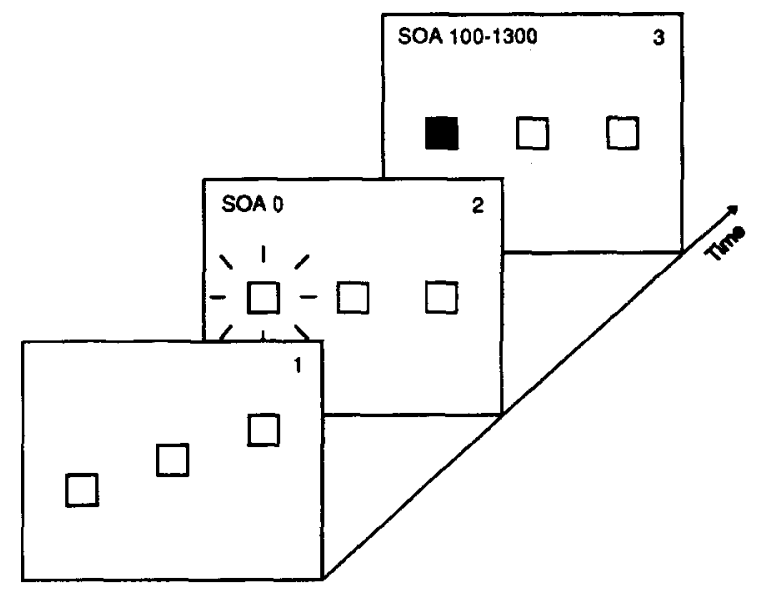

B)

Moving condition

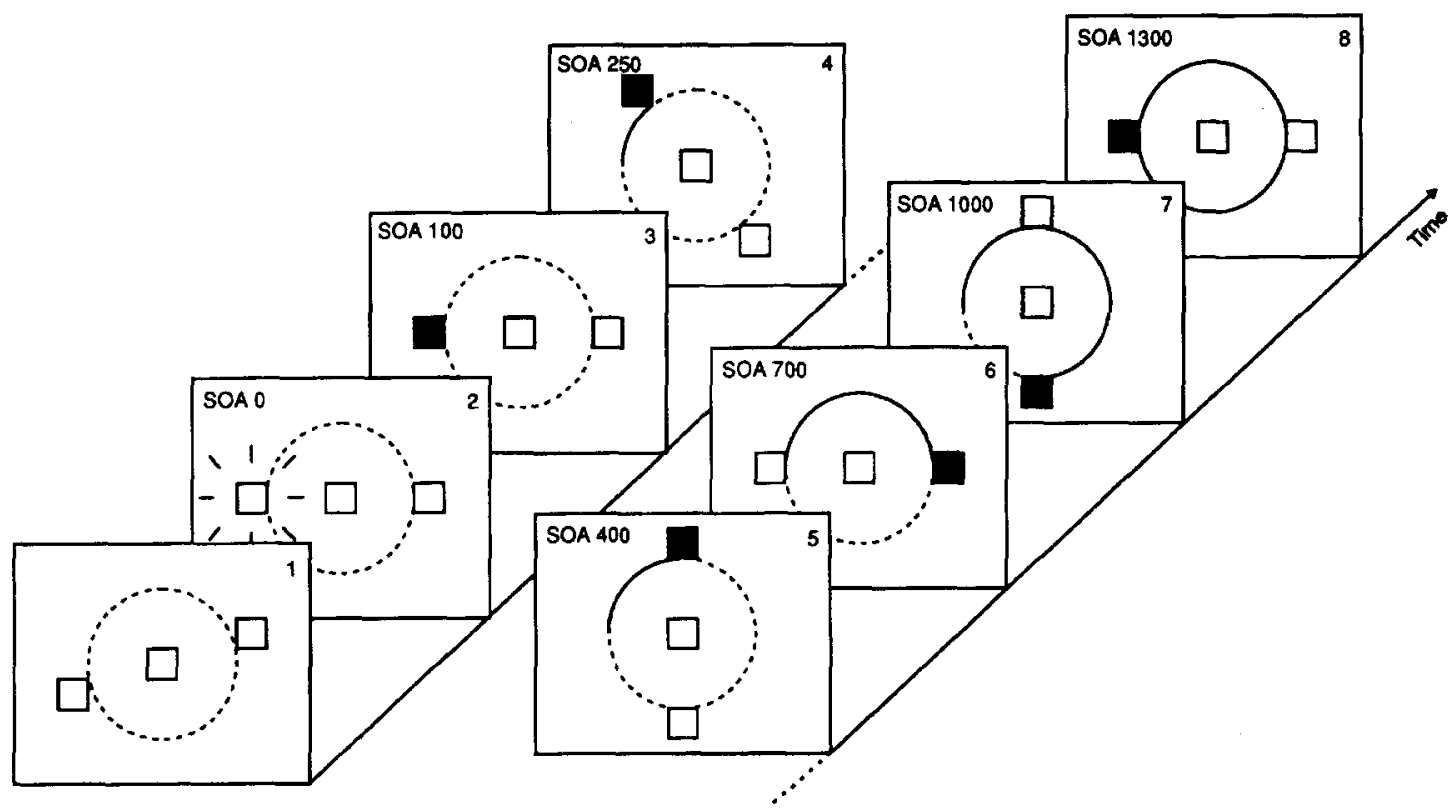

Figure 1. Sequence of events on (A) stationary trials and (B) moving trials. From Frame 3 onwards, the filled box represents the position of the cued box, and the unfilled (peripheral) box represents the position of the uncued box, at the respective SOA. 
the midline), where they remained for $100 \mathrm{msec}$. This procedure, which was the same for the stationary and moving conditions, was followed in order to replicate the experiments of Tipper et al. Next, a flash (the cue) appeared in the left peripheral box for $100 \mathrm{msec}$ (i.e., unlike Tipper et al., the cued box was fixed, left, rather than variable, left or right; see Figures 1A and 1B). This flash consisted of a brightening of the spots constituting that box. It was spatially uninformative as to the target location. The cue was then followed by the target at varying SOAs. Five hundred milliseconds after cue onset, the central box was brightened for $100 \mathrm{msec}$ (in the study of Tipper et al., the center flash occurred $200 \mathrm{msec}$ after cue onset). This was done to draw attention back to the center-which, according to Posner and Cohen (1984), helps one to observe IOR unaffected by visuospatial attention.

In the moving condition (see Figure 1B), the clockwise rotation of the peripheral boxes began immediately after cue offset (in the study of Tipper et al., the box motion commenced $200 \mathrm{msec}$ after cue onset). The complete rotation took $1,200 \mathrm{msec}$. In pilot work, a 900msec rotation was used; but, again, subjects found the task "uncomfortable" under that condition. The positions of the peripheral boxes were updated 120 times during the rotation, producing a smooth, continuous form of motion (in contrast, Tipper et al. used only 32 movement steps with a box eccentricity of $7.2^{\circ}$, which resulted in a jerky form of motion). The target, a bright (filled) square of size $.06^{\circ}$, appeared in any of the three boxes at random. The target, once presented, remained visible inside (i.e., moved with) its box until a response was made (in contrast, Tipper et al. presented their target for a relatively short time, $67 \mathrm{msec}$, only during pauses between movement steps). When a response had been made, the peripheral boxes repositioned below and above the horizontal midline to begin the next trial.

The procedure for the stationary condition (see Figure 1A) was initially the same as that for the moving trials. The difference occurred after cue offset, when there was no movement of the peripheral boxes.

In both conditions, there were six cue-target SOAs, which varied randomly: $100,250,400,700,1,000$, and $1,300 \mathrm{msec}$. In the moving condition, the position of the cued box was left, left-upper, upper, right, lower, and left, respectively (see Figure 1B). Note that the target occurred before the central brightening at the 100-, 250-, and 400 -msec SOAs, and after the central brightening at the 700-, 1,000-, and 1,300-msec SOAs.

Each condition consisted of 1,440 trials, which were presented in 30 blocks of 48 trials. For each SOA, there were 100 central-box, 50 cued-box, and 50 uncued-box target trials. The 50/50 ratio of cued and uncued targets meant that the cue was uninformative as to the location of the target (as was the case in the study of Tipper et al.). The large proportion of central target trials were included to ensure that the subjects maintained eye fixation on the central box. There were 240 catch trials on which no target appeared, and the subject had to withhold a response. Each block started with five unrecorded warmup trials.

The subjects were asked to maintain eye fixation on the central box and respond as quickly as possible to a target by pressing a single key using their preferred hand. Their simple RTs (to the onset of a target) were measured. There was audible feedback (a bleep) when a response was incorrect (i.e., either an anticipation on a target trial or a response on a catch trial). The subjects were advised that they were permitted to break after any block to prevent fatigue. They were familiarized with the task in a practice session of 192 (unrecorded) trials.

\section{Results}

RTs. For each subject, the mean correct RT was calculated for each target location (central, cued, and uncued) and $\operatorname{SOA}(100,250,400,700,1,000$, and $1,300 \mathrm{msec})$ in the stationary and moving conditions. The group mean RTs for each experimental condition (stationary and moving) are presented in Table 1 . The corresponding patterns of facilitation/inhibition across SOA are shown in Figure 2. The graphs show retinal or environmental IOR in the stationary condition but no consistent evidence of dynamic, object-centered IOR in the moving condition.

The RT data were examined by a repeated measures analysis of variance (ANOVA), with main terms for condition (stationary/moving), target position, and SOA. Significant main effects and interactions are listed in Table 2.

Central targets were responded to faster than were targets in cued and uncued boxes (main effect of target position), and RTs decreased with increasing SOA (presumably due to "alerting"; Posner, 1978) (main effect of SOA). The SOA effect was more marked in the moving condition, which showed a marked decrease in RTs after the 700-msec SOA (condition $\times$ SOA interaction). The cause of the three-way interaction was as follows: RTs to central targets showed a relatively strong decrease between the 100- and 250-msec SOAs (alerting); RTs to targets at cued and uncued positions showed an increase at the 400- and $700-\mathrm{msec}$ SOAs (particularly marked in the moving con-

Table 1

Mean Reaction Times and Facilitation/Inhibition (in Milliseconds) in the Stationary and Moving Conditions of Experiment 1

\begin{tabular}{|c|c|c|c|c|c|c|}
\hline \multirow[b]{2}{*}{ Condition } & \multicolumn{6}{|c|}{ SOA (in milliseconds) } \\
\hline & 100 & 250 & 400 & 700 & 1,000 & 1,300 \\
\hline \multicolumn{7}{|l|}{ Stationary } \\
\hline Central & 360 & 337 & 343 & 332 & 326 & 331 \\
\hline Cued & 391 & $386_{1}$ & $404_{1}$ & $381_{1}$ & $363_{1}$ & 362 \\
\hline Uncued & $400_{\mathrm{r}}$ & $385_{\mathrm{r}}$ & $398_{r}$ & 367 & $345_{r}$ & $341_{r}$ \\
\hline Facilitation/Inhibition & +9 & -1 & --6 & $-14^{*}$ & $-18^{*}$ & $-21^{*}$ \\
\hline \multicolumn{7}{|l|}{ Moving } \\
\hline Central & 351 & 315 & 314 & 312 & 294 & 268 \\
\hline Cued & $410_{1}$ & $400_{\mathrm{tl}}$ & $402_{\mathrm{t}}$ & $425_{r}$ & $386_{b}$ & $339_{1}$ \\
\hline Uncued & $413_{\mathrm{r}}$ & $404_{\mathrm{br}}$ & $424 b$ & $438_{1}$ & $378_{\mathrm{t}}$ & $325_{\mathrm{r}}$ \\
\hline Facilitation/Inhibition & +3 & +4 & $+22^{*}$ & $+13^{*}$ & -8 & $-14^{*}$ \\
\hline
\end{tabular}




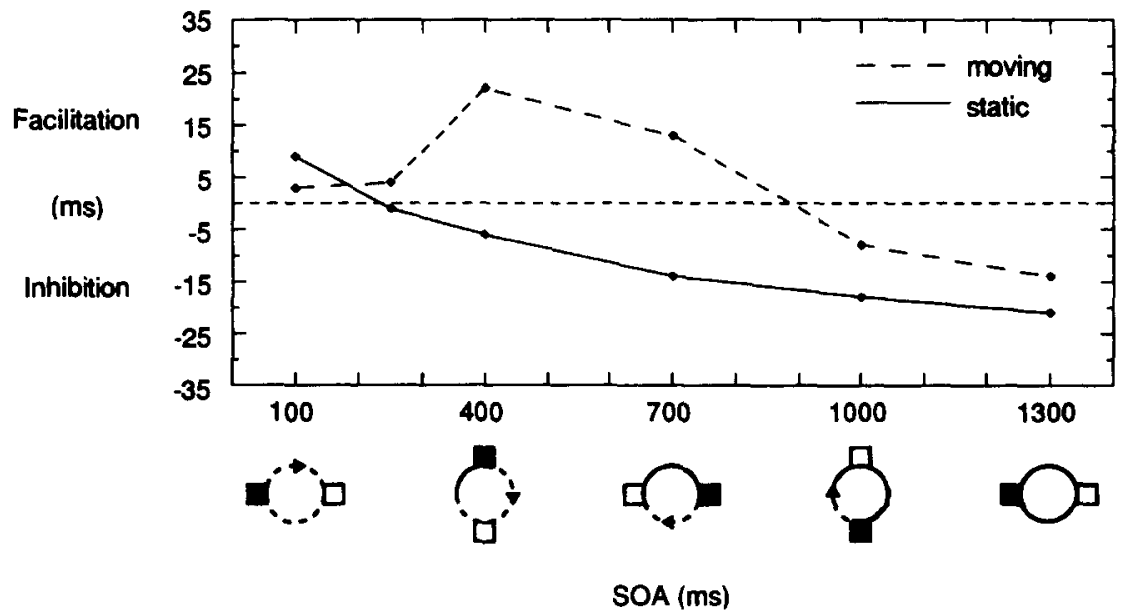

Figure 2. Mean reaction time facilitation/inhibition as a function of cue-target SOA, separately for the stationary and moving conditions. The icons below the $x$-axis indicate the positions of the cued (filled) and uncued (unfilled) boxes at the respective SOA in the moving condition.

dition), coinciding with the flash at the central position (which occurred 500 msec after cue onset).

The most important result with respect to dynamic, object-centered IOR was the relative performance, across SOA, for cued and uncued positions (boxes) under the stationary and moving conditions. In the stationary condition, at the 100-msec SOA, RTs tended to be faster to targets in the cued box than in the uncued box; at SOAs longer than $250 \mathrm{msec}$, RTs were slower to cued-box targets than to uncued-box targets. This pattern conforms with the standard retinal or environmental IOR effect. In the moving condition, RTs to targets in the cued box showed some (nonsignificant) facilitation at the 100- and 250-msec SOAs, marked facilitation at the 400 - and 700 -msec SOAs, and inhibition at the 1,000-msec and, most markedly, 1,300msec SOAs. This pattern is unexpected, requiring further consideration.

Errors. Anticipation errors on target trials and response errors on catch trials were rare overall (less than $1 \%$ on average, with no subject above 2\%). An ANOVA of the arcsine-transformed anticipation rates, with the factors condition (stationary/moving), target position, and SOA, failed to reveal any significant effects. However, as could be expected, virtually no anticipations were made in the range of SOAs between 100 and $400 \mathrm{msec}$; if subjects were prone to producing anticipations, these tended to be made at longer SOAs.

\section{Discussion}

The stationary condition showed early facilitation for the cued box followed by inhibition at longer SOAs, replicating the standard (retinal or environmental) IOR effect.

In the moving condition, the relatively small facilitation at the 100-msec SOA might have been due to the movement onset (starting immediately after cue offset) interfering with attention capture by the cue and/or the movement onset masking the target. The unexpected facilitation at intermediate SOAs (i.e., for targets in the upper and right positions) has two possible explanations. The first is that subjects "track" (i.e., attend to) the cued box when movement commences until the central flash attracts attention; given that locking on to the cued box takes time (to detect the movement, etc.), facilitation would become manifest only after some delay. Alternatively, subjects have a natural tendency to track one of the moving objects - that which moves from left to right above the horizontal midline, regardless of whether it was cued or uncued. Of course, this tracking preference may only apply in the present situation in which there is another object that moves from right to left below the midline. Also, it may reflect two independent preferences: tracking of the object that moves from left to right (rather than from right to left) and/or tracking of the object that moves above the midline (rather than below; see discussion below for a more detailed consideration of these possibilities).

According to the first account (tracking of the cued box), the central flash interrupts tracking. Therefore, the inhibition at the 1,000- and 1,300-msec SOAs would reflect dynamic, object-centered IOR. However, there are two

Table 2

Summary of Reaction Time Analysis of Variance Effects in Experiment 1

\begin{tabular}{lrrrr}
\hline \multicolumn{1}{c}{ Effect } & $F$ & $d f$ & $M S_{\mathrm{e}}$ & $p$ \\
\hline Main Effects & & & & \\
$\quad$ TP & 174.13 & 2,18 & .0009 & .001 \\
SOA & 34.66 & 5,45 & .0009 & .001 \\
Interactions & & & & \\
C $\times$ TP & 45.37 & 2,18 & .0005 & .001 \\
C $\times$ SOA & 14.28 & 5,45 & .0005 & .001 \\
TP $\times$ SOA & 9.63 & 10,90 & .0002 & .001 \\
C $\times$ TP $\times$ SOA & 4.28 & 10,90 & .0002 & .001 \\
\hline
\end{tabular}

Note $-\mathrm{C}=$ condition (stationary $/$ moving); $\mathrm{TP}=$ target position; $\mathrm{SOA}=$ stimulus onset asynchrony. 
A)

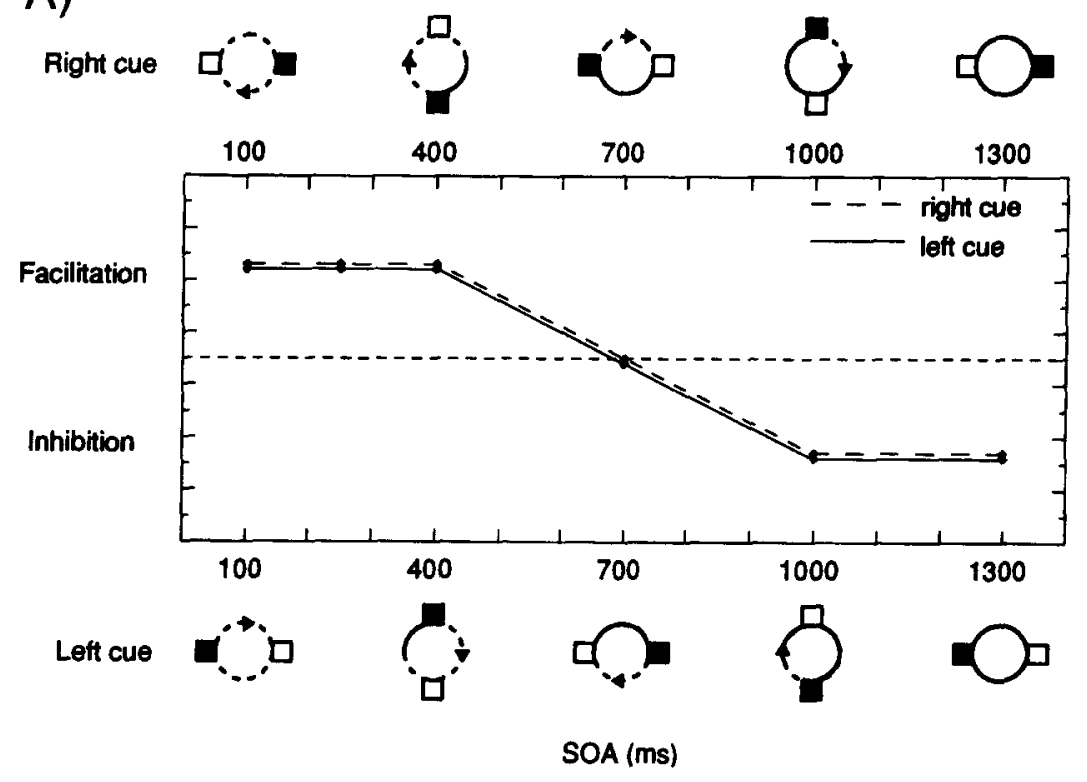

B)

Right cue
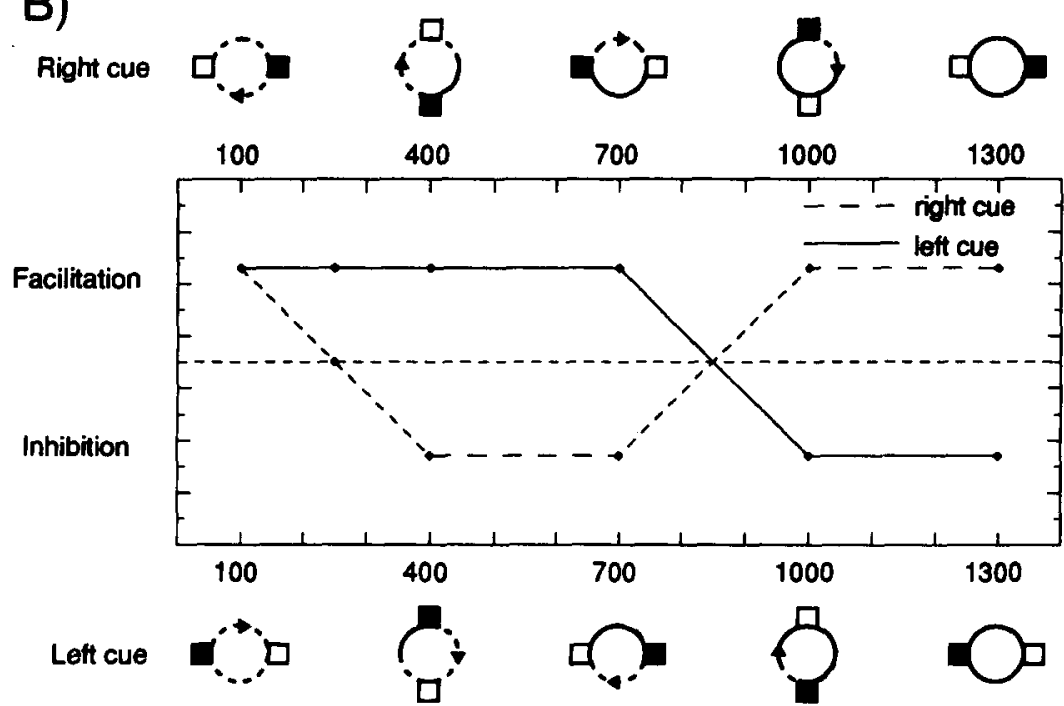

Figure 3. Contrasting predictions for reaction time facilitation/inhibition as a function of cue-target SOA, separately for left- and right-side cues (idealized data). The icons along the $x$-axis indicate the positions of the cued (filled) and uncued (unfilled) boxes at the respective SOA. Panel $A$ illustrates the pattern of results expected if subjects track the cued box, with tracking being interrupted by the central flash (500msec SOA). Panel B illustrates the pattern of results expected if subjects track whatever box moves from left to right.

problems with this account. First, it fails to explain the facilitation for the right position at the 700-msec SOA, which suggests that tracking was not interrupted by the central flash. Second, reliable inhibition was only found at the $1,300-\mathrm{msec}$ SOA when the cued box had returned to its original (left) position. This would suggest that the only position inhibited was the physical location of the cue, contrary to the findings of Tipper et al. (1991). Note that, if IOR were confined to the physical location of the cue, there would be another account of the facilitation at the 700-msec SOA. At this time, the uncued box was at the physical location of the cue and, therefore, was subject to IOR. This would have slowed RTs to targets in the uncued relative to the cued box, resulting in net facilitation.

According to the second account, subjects track the box that moves from left to right above the midline (rather than the box that moves from right to left below the midline), and tracking is not (completely) interrupted by the central flash. This account would explain the RT disadvantage for the cued box (inhibition) at the 1,000- and 1,300-msec SOAs 
Table 3

Mean Reaction Times and Facilitation/Inhibition (in Milliseconds) in the Stationary and Moving Conditions of Experiment 2

\begin{tabular}{|c|c|c|c|c|c|c|c|c|}
\hline \multirow[b]{3}{*}{ Cue } & \multicolumn{2}{|c|}{ Stationary } & \multicolumn{6}{|c|}{ Moving } \\
\hline & \multicolumn{2}{|c|}{ SOA (in milliseconds) } & \multicolumn{6}{|c|}{ SOA (in milliseconds) } \\
\hline & 100 & 1,300 & 100 & 250 & 400 & 700 & 1,000 & 1,300 \\
\hline \multicolumn{9}{|l|}{ Left } \\
\hline Central & 317 & 297 & 343 & 310 & 313 & 315 & 299 & 270 \\
\hline Cued & $358_{1}$ & $317_{1}$ & $387_{1}$ & $379_{\mathrm{tl}}$ & $382_{t}$ & $410_{r}$ & $377_{b}$ & $325_{1}$ \\
\hline Uncued & $360_{\mathrm{r}}$ & $290_{\mathrm{r}}$ & $392_{r}$ & $383_{\mathrm{br}}$ & $400_{b}$ & $412_{1}$ & $359_{1}$ & $309_{\mathrm{r}}$ \\
\hline Facilitation/Inhibition & +2 & $-27^{*}$ & +5 & +4 & $+18^{*}$ & +2 & $-18^{*}$ & $-16^{*}$ \\
\hline \multicolumn{9}{|l|}{ Right } \\
\hline Central & 330 & 292 & 347 & 322 & 314 & 323 & 307 & 269 \\
\hline Cued & $352_{r}$ & $308_{r}$ & $385_{\tau}$ & $381_{\mathrm{br}}$ & $394_{b}$ & $416_{1}$ & $362_{t}$ & $319_{\mathrm{r}}$ \\
\hline Uncued & $360_{1}$ & $303_{1}$ & $416_{1}$ & $381_{t}$ & $383_{t}$ & $409_{\mathrm{r}}$ & $376_{b}$ & $317_{1}$ \\
\hline Facilitation/Inhibition & +8 & -5 & $+31^{*}$ & 0 & -11 & -6 & $+14^{*}$ & -2 \\
\hline
\end{tabular}

Note $-\mathrm{l}=$ left position; $\mathrm{r}=$ right position; $\mathrm{t}=$ top position; $\mathrm{b}=$ bottom position. + indicates facilitation; - indicates inhibition. *Significant, $\alpha=.05$.

in terms of the tracking of the uncued box, which, at those times, moved above the midline from left to right. Assuming that it takes time, after the 700-msec SOA, to switch attention from the cued box (which, at that SOA, started to move below the midline from right to left) to the uncued box (which started to move above the midline from left to right), facilitation would be observed only for boxes moving through the upper and right parts of the display.

These two accounts were pitted against each other in Experiment 2.

\section{EXPERIMENT 2}

If the first account (tracking of the cued box) is correct, then which box is cued-the left or the right one--should be important. In particular, subjects should show an initial advantage (facilitation) for the upper and right positions with a left-side cue and for the lower and left positions with a right-side cue; after the central flash (interrupting tracking), subjects should show a disadvantage (dynamic, object-centered IOR) for the lower and left positions with left-side cues and for the upper and right positions with right-side cues. If the second account is correct (tracking of whatever box moves above the midline from left to right), subjects should show faster responses to targets in the upper and right locations of the display, irrespective of the cued box (left or right), except for an early advantage for the left-cued position (when the cue attracts attention). To test these contrasting predictions, Experiment 2 presented not only left-side cues (as in Experiment 1) but also right-side cues. The differential patterns of facilitation/ inhibition across SOA expected on the two accounts are illustrated in Figure 3 (idealized data).

Recall that, in Experiment 1, the facilitation from the cue (at the 100-msec SOA) was relatively small, particularly in the moving condition. This may have been due to the onset of the movement interfering with the cuing and to the cue being spatially uninformative. To enhance the effectiveness of the cue, Experiment 2 used a peripheral dimming of the cued box (i.e., the spots composing the box were switched off and on, with a 100-msec blank interval between box offset and onset), which produced a stronger luminance change than did the brightening cue in Experiment 1 (note that Tipper et al., 1991, used a dimming cue). Furthermore, the cue was made spatially informative at all SOAs shorter than $500 \mathrm{msec}$ (i.e., all SOAs before the central flash). This is not uncommon in IOR experiments (e.g., see Posner \& Cohen, 1984.)

\section{Method}

Subjects. Eight subjects ( 5 males and 3 females, with ages ranging from 18 to 36 years) participated in Experiment 2. They all had normal or corrected-to-normal vision. All subjects were righthanded. They were paid $£ 3.00$ per session.

Procedure. There were two sessions of each condition (stationary/ moving), with conditions counterbalanced across subjects and sessions. The cue could appear in either the left or the right peripheral box, with left- and right-side cues presented in random order. The box motion was always clockwise in the moving condition. In that condition, for each cued location (left and right), there were 1,320 trials $(6$ SOAs $\times 200$ target trials +120 catch trials, with target trials consisting of 100 central-box, 80 or 50 cued-box, and 20 or 50 uncued-box trials). In the stationary control condition, there were only 440 trials for each cued location. This reduction was achieved by using only two SOAs ( 100 and $1,300 \mathrm{msec})$, which was deemed sufficient to measure the early facilitation and late IOR effects (2 SOAs $\times 400 \mathrm{central} / \mathrm{cued} / \mathrm{uncued}$ trials $+40 \mathrm{catch}$ trials). Note that, at the 100-, 250-, and 400-msec SOAs, cued-box targets were four times more frequent than were uncued-box targets (i.e., the cue validity was $80 \%$ ); at longer SOAs, cue validity was $50 \%$ (as in Experiment 1). The subjects were fully informed of these contingencies. The total number of trials performed by each subject was 3,520.

In all other respects, the method was the same as that in Experiment 1 .

\section{Results}

RTs. The group mean RTs for the two experimental conditions (stationary and moving) are listed in Table 3. The corresponding patterns of facilitation/inhibition across SOA are shown in Figures 4A and 4B. The figures show retinal or environmental IOR in the stationary condition (Figure 4A) but no evidence of dynamic, objectcentered IOR in the moving condition (Figure 4B). Rather, 

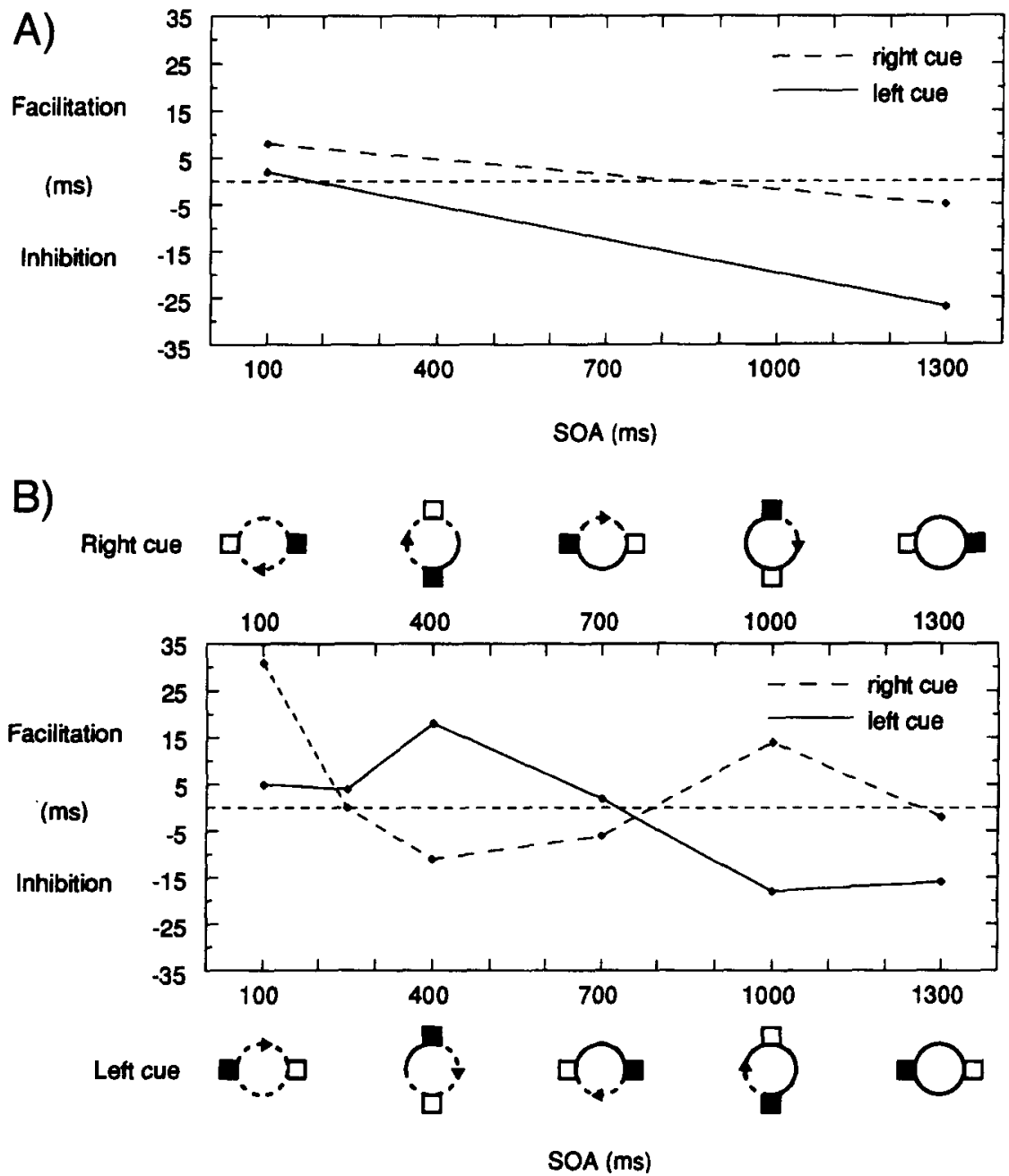

Figure 4. Mean reaction time facilitation/inhibition as a function of cue-target SOA, separately for left-and right-side cues in the (A) stationary condition and (B) moving condition. The icons along the $x$-axis in panel $B$ indicate the positions of the cued (filled) and uncued (unfilled) boxes at the respective SOA.

performance in the latter condition conformed with attentive tracking of the left-to-right moving box.

The RT data were examined by a repeated measures ANOVA, with main terms for cue position, target position, and SOA. The stationary and moving conditions were treated with separate ANOVAs. Significant main effects and interactions are listed in Table 4.

The stationary data conform with the standard finding of early facilitation $(5 \mathrm{msec})$ and late IOR $(-16 \mathrm{msec})$ (target position $\times$ SOA interaction). This pattern was not significantly influenced by cue position (left or right), although there was some tendency for early facilitation to be greater ( $8 \mathrm{vs} .2 \mathrm{msec}$ ) and late inhibition to be smaller $(-5$ vs. $-27 \mathrm{msec})$ with right cues, suggesting a bias toward targets on the right side of fixation (right-side bias).

With regard to the moving data, if one considers the target position $\times$ SOA interaction only, there appears to be early facilitation (100-msec SOA) and late inhibition (1,300-msec SOA), with a reasonably gradual transition at intermediate SOAs. However, the picture becomes more complex when cue position is taken into consideration (see Table 3 and Figure 4b). Both the left- and the rightcued position showed facilitation at the $100-\mathrm{msec}$ SOA, though more markedly for the right. At the $400-\mathrm{msec}$ SOA, the left-cued box, which at that time occupied the upper position, exhibited facilitation, and the right-cued box, which occupied the lower position, exhibited inhibition. At the 1,000-msec SOA, the left-cued box, which occupied the lower position, showed inhibition, and the right-cued box, occupying the upper position, exhibited facilitation. At the 700-msec SOA, the left-cued box, occupying the right position, showed (nonsignificant) facilitation, and the left-cued box, in the lower position, showed inhibition. At the 1,300-msec SOA, when the cued boxes had returned to their original positions, the left-cued box exhibited inhibition and the right-cued box exhibited (nonsignificant) inhibition. 
Table 4

Summary of Reaction Time Analysis of Variance Effects in Experiment 2

\begin{tabular}{|c|c|c|c|c|}
\hline Effect & $F$ & $d f$ & $M S_{\mathrm{e}}$ & $p$ \\
\hline \multicolumn{5}{|c|}{ Stationary Condition } \\
\hline \multicolumn{5}{|l|}{ Main Effects } \\
\hline$T P$ & 9.12 & 2,14 & .0010 & .005 \\
\hline $\mathrm{SOA}$ & 24.93 & 1,7 & .0044 & .005 \\
\hline \multicolumn{5}{|l|}{ Interactions } \\
\hline $\mathrm{TP} \times \mathrm{SOA}$ & 26.75 & 2,14 & .0003 & .001 \\
\hline \multicolumn{5}{|c|}{ Moving Condition } \\
\hline \multicolumn{5}{|l|}{ Main Effects } \\
\hline $\mathrm{CP}$ & 6.56 & 1,7 & .0003 & .05 \\
\hline TP & 107.36 & 2,14 & .0026 & .001 \\
\hline SOA & 22.19 & 5,35 & .0037 & .001 \\
\hline \multicolumn{5}{|l|}{ Interactions } \\
\hline $\mathrm{TP} \times \mathrm{SOA}$ & 11.48 & 5,35 & .0003 & .001 \\
\hline $\mathrm{CP} \times \mathrm{TP} \times \mathrm{SOA}$ & 2.80 & 10,70 & .0004 & .01 \\
\hline
\end{tabular}

Note $-\mathrm{CP}=$ cue position; $\mathrm{TP}=$ target position; $\mathrm{SOA}=$ stimulus onset asynchrony.

Errors. Anticipation errors on target trials and response errors on catch trials were rare overall (less than $1 \%$ on average, with no subject above $2 \%$ ). The arcsine-transformed anticipation rates in the stationary and moving conditions were subjected to separate ANOVAs, with cue position, target position, and SOA as factors. No significant effects were found. However, anticipations were observed only at SOAs greater than $400 \mathrm{msec}$. At the $1,300-\mathrm{msec}$ SOA, slightly more anticipations were made in the stationary condition $(2.6 \%)$ than in the moving condition $(1.5 \%)$. This difference was probably due to the fact that there was only one long SOA in the stationary condition.

\section{Discussion}

Overall, the pattern of facilitation/inhibition in the moving condition is consistent with the second account outlined above-namely, subjects have a natural tendency (bias) to track objects that move above the horizontal midline from left to right. This is at variance with the first account, according to which the cued box should be tracked (at least before the presentation of the central flash). This can clearly be seen at the 400-msec SOA, when RTs to targets in the rightcued box occupying the lower position were slower than RTs to targets in the left-uncued box occupying the upper position - despite the fact that the cue was still valid. This indicates that the preferred tracking direction overrides cue validity effects. The proposed tendency to track objects that move on an up-down trajectory from left to right seems to reflect a "realistic" adjustment to the constraints of our natural (up-down "ballistic" object movement) and cultural environments (left-to-right reading direction).

There was no evidence of dynamic, object-centered IOR at SOAs longer than $400 \mathrm{msec}$ when the cue was no longer valid. If anything, there was evidence of IOR only for the physical location of the cue (at the 1,300-msec SOA, both left- and right-cued boxes showed inhibition, though not significant with right-side cues). However, at the 700-and
1,000 -msec SOAs, only the boxes occupying the left and lower positions, respectively, showed inhibition, which is best explained in terms of preferred tracking direction rather than IOR.

\section{EXPERIMENT 3}

Experiments 1 and 2 produced no evidence of dynamic, object-centered IOR. However, they differed from the experiments of Tipper et al. (1991) in several respects that might be crucial for dynamic, object-centered IOR to occur. First, Experiments 1 and 2 used peripheral box and target eccentricities of $1.5^{\circ}$, whereas Tipper et al. used eccentricities of $7.2^{\circ}$. Second, Tipper et al. used a movement speed of approximately 1 rotation/second, whereas Experiments 1 and 2 used 0.83 rotations/second. Third, Tipper et al. used only 32 movement steps for a complete rotation (120 steps were used in the present experiments), which, together with the larger eccentricity, produced a rather discontinuous form of motion. In summary, Tipper et al. used "long-range apparent motion," whereas the present experiments used "short-range apparent motion."

As originally proposed by Braddick (1974), short-range motion consists of the activation of low-level motion detectors that respond under conditions of small spatial displacements, short stimulus durations, and short interstimulus intervals (ISIs). In contrast, long-range apparent motion consists of higher level perceptual activity that operates over relatively larger spatial displacements, longer stimulus durations, and longer ISIs. These two types of apparent motion also differ with respect to their attentional requirements (Dick, Ullman, \& Sagi, 1987; Ivry \& Cohen, 1990). For example, using a standard visual search task, Ivry and Cohen found evidence suggesting that short-range apparent motion is processed preattentively, whereas the processing of long-range apparent motion involves attention.

Possibly, dynamic, object-centered IOR is obtained only under the long-range apparent motion conditions used by Tipper et al. If long-range apparent motion involves an attentional object-displacement system (e.g., Cavanagh, 1992), it is possible that once an object is negatively tagged, the spatial coordinates of the tag are dynamically updated with the movement of the object. For example, the tag may be recorded in an "object file," which also contains an index that keeps track of the object's changing environmental position (Kahneman, Treisman, \& Gibbs, 1992; Pylyshyn \& Storm, 1988).

Experiment 3 tested whether dynamic, object-centered IOR critically depends on the form of apparent motion of the peripheral boxes (long range rather than short range). The form of motion was manipulated by varying the number of frames per complete rotation (with box eccentricity, $7.2^{\circ}$, and rotation duration, $1,200 \mathrm{msec}$, kept constant). This number varied from 30 frames, which is close to the 32 frames used by Tipper et al. and well within the range typically regarded as long-range apparent motion, to 120 frames, which is well within the range of short-range apparent motion. 


\section{Method}

Subjects. Nine subjects ( 5 males and 4 females, with ages ranging from 18 to 37 years) participated in Experiment 3. They all had normal or corrected-to-normal vision. All subjects were right-handed. They were paid $£ 4.00$ per hour.

Procedure. The procedure was the same as that in Experiment 2 except for the following differences. In the moving condition, there were three levels of apparent motion, implemented by varying the number of frames (displacements) required for a full rotation of the peripheral boxes: 30,60 , or 120 frames. Note that Experiment 3 used the same peripheral box and target eccentricities as used by Tipper et al. (1991)-namely, 7.2 $2^{\circ}$. Furthermore, the 250-msec SOA was dropped, and the peripheral cue was made more salient by presenting an on-off-on-off-on-off flash (where each on and off phase lasted $20 \mathrm{msec}$, such that the time between the onset of the first flash and the offset of the third flash was $100 \mathrm{msec}$ ).

The form of apparent motion was blocked. Cue position (left or right box), target position (central, cued, or uncued box), and SOA (100, $400,700,1,000$, or $1,300 \mathrm{msec}$ ) were randomized within blocks. Experiment 3 was conducted over three sessions. Each session consisted of three blocks of 1,200 trials, with each block presenting one of the three apparent motion conditions. Within a session, the form of apparent motion was varied in either ascending or descending order (with the order counterbalanced across subjects and sessions as well as possible). Each subject completed 7,200 trials in the moving condition.

There was also a stationary control condition, which will be presented below as Experiment 5 .

In all other respects, Experiment 3 was the same as Experiment 2.

\section{Results}

RTs. Table 5 presents the group mean RTs, across SOA, for targets at central, cued, and uncued positions, separately for left and right cues (cue position $\times$ target position $\times$ SOA interaction). Figure 5 illustrates the corresponding patterns of facilitation/inhibition across SOA, which were much the same as those in Experiment 2.
Table 5

Mean Reaction Times and Facilitation/Inhibition (in Milliseconds) in Experiment 3

\begin{tabular}{lccccc}
\hline & \multicolumn{5}{c}{ SOA (in milliseconds) } \\
\cline { 2 - 7 } \multicolumn{1}{c}{ Cue } & 100 & 400 & 700 & 1,000 & 1,300 \\
\hline Left & & & & & \\
$\quad$ Central & 344 & 322 & 318 & 301 & 226 \\
$\quad$ Cued & $347_{\mathrm{I}}$ & $386_{\mathrm{t}}$ & $370_{\mathrm{r}}$ & $359_{\mathrm{b}}$ & $245_{\mathrm{I}}$ \\
$\quad$ Uncued & $366_{\mathrm{r}}$ & $396_{\mathrm{b}}$ & $373_{\mathrm{l}}$ & $349_{\mathrm{t}}$ & $232_{\mathrm{r}}$ \\
$\quad$ Facilitation/Inhibition & $+19^{*}$ & +10 & +3 & -10 & -13 \\
Right & & & & & \\
$\quad$ Central & 348 & 321 & 317 & 303 & 225 \\
$\quad$ Cued & $357_{\mathrm{r}}$ & $400_{\mathrm{b}}$ & $375_{1}$ & $349_{\mathrm{l}}$ & $234_{\mathrm{r}}$ \\
$\quad$ Uncued & $385_{\mathrm{I}}$ & $386_{\mathrm{t}}$ & $372_{\mathrm{r}}$ & $362_{\mathrm{b}}$ & $242_{1}$ \\
$\quad$ Facilitation/Inhibition & $+30^{*}$ & -14 & -3 & +13 & +8 \\
\hline
\end{tabular}

Note- $\mathrm{l}=$ left position; $\mathbf{r}=$ right position; $\mathrm{t}=$ top position; $\mathrm{b}=$ bottom position. + indicates facilitation; - indicates inhibition. *Significant, $\alpha=.05$.

The RT data were examined by a repeated measures ANOVA, with main terms for type of motion, cue position, target position, and SOA. Significant main effects and interactions are listed in Table 6.

Most importantly, the type of motion did not critically influence the pattern of facilitation/inhibition for left- and right-side cues across SOA [the four-way interaction was not significant, $F(16,128)=0.83$ ], although long-range apparent motion ( 30 frames per rotation) appeared to reduce any facilitatory and inhibitory effects except for the initial facilitation (100-msec SOA) for the cued position (left or right). Also, it tended to prolong RTs overall (main effect).

As can be seen from Figure 5, the patterns of facilitation/ inhibition across SOA were essentially the same as those

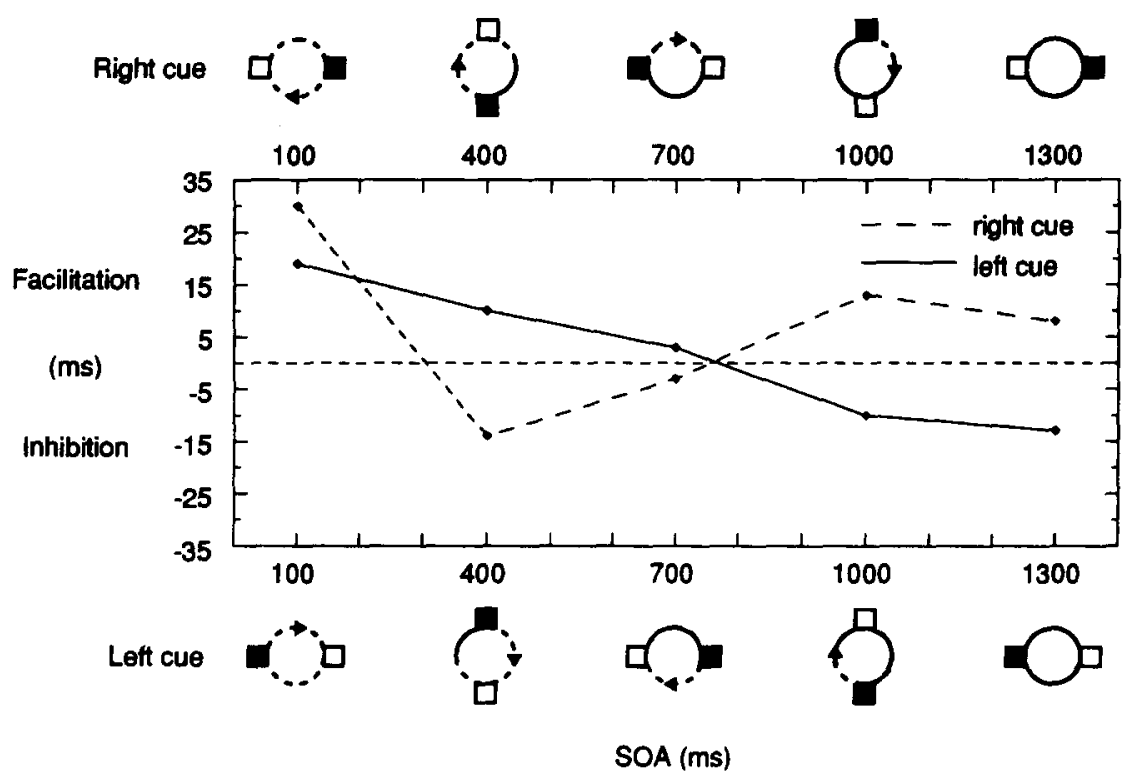

Figure 5. Mean reaction time facilitation/inhibition as a function of cue-target SOA, separately for left- and right-side cues. The icons along the $x$-axis indicate the positions of the cued (filled) and uncued (unfilled) boxes at the respective SOA. 
Table 6

Summary of Reaction Time Analysis of Variance Effects in Experiment 3

\begin{tabular}{lrlll}
\hline \multicolumn{1}{r}{ Effect } & \multicolumn{1}{c}{$F$} & $d f$ & $M S_{\mathrm{e}}$ & $p$ \\
\hline Main Effects & & & & \\
FM & 3.30 & 2,16 & .0049 & .075 \\
CP & 22.98 & 1,8 & .0049 & .005 \\
TP & 61.89 & 2,16 & .0023 & .001 \\
SOA & 95.22 & 4,32 & .0052 & .001 \\
Interactions & & & & \\
FM $\times$ TP & 12.37 & 8,64 & .0007 & .001 \\
CP $\times$ SOA & 3.45 & 4,32 & .0002 & .025 \\
TP $\times$ SOA & 26.09 & 8,64 & .0005 & .001 \\
FM $\times$ TP $\times$ SOA & 2.16 & 1,128 & .0002 & .025 \\
CP $\times$ TP $\times$ SOA & 2.69 & 8,64 & .0005 & .025 \\
\hline
\end{tabular}

Note- $F M=$ form of motion; $C P=$ cued position; $T P=$ target position; $\mathrm{SOA}=$ stimulus onset asynchrony.

observed in Experiment 2. There were sizable facilitatory effects for the cued (left or right) position at the 100-msec SOA (somewhat more marked for right cues). At longer SOAs, targets at the top and right positions showed facilitation, and targets at bottom and left positions showed inhibition. In other words, there was no evidence of dynamic, object-centered IOR for cued boxes at SOAs longer than $500 \mathrm{msec}$; rather, any inhibition manifest at those SOAs was associated with the bottom and left positions (irrespective of whether the cued or uncued box happened to occupy those positions), consistent with preferred attentive tracking of any box that moves above the midline from left to right.

Errors. Anticipation and catch-trial errors were rare overall (less than $1 \%$ on average, with no subject above $2 \%$ ). An ANOVA of the arcsine-transformed anticipation rates, with the factors type of motion, cue position, target position, and SOA, failed to reveal any significant effects. However, anticipations tended to be made only at longer SOAs (<400 msec).

\section{Discussion}

The finding that the attentive-tracking preference was not affected by the type of motion, short or long range, adds support to Cavanagh's (1993) suggestion that

a different dichotomy may be more appropriate. Specifically, low-level detectors are available to signal stimulus displacement for a variety of ... stimulus attributes. [The detectors form] a dense array ... analyzing image features in parallel. A second motion system is available that [involves] attentive tracking [of an object] ... without [necessarily] engaging any eye movements. ... [This] second source of motion signals ... relies on the displacements of the focus of attention. (p. 178)

The present findings suggest that only one of two objects (boxes) can be tracked at any one time by this second system. This seems to be at variance with Pylyshyn and Storm (1988), who proposed that four to five objects could be tracked in parallel. It is possible that multiple objects may be tracked simultaneously (in particular, when they form a coherent group; Yantis, 1992) but that only one can be attentively monitored for a change (e.g., a luminance increment) at any one time.

In summary, Experiment 3 replicated the patterns of facilitation/inhibition across SOA found in Experiment 2. It produced no evidence for dynamic, object-centered IOR along the lines of Tipper et al. Therefore, the type of motion (and the eccentricity) of the peripheral boxes is not crucial for observing dynamic, object-centered IOR.

\section{EXPERIMENT 4}

According to the attentive-tracking account outlined above, there is a preference to track objects that move from left to right in the upper half of the field. This bias for targets in the upper field seems to be at variance with other findings (with static displays) according to which manual responses are faster to targets in the lower part of the field (e.g., Gawryszewski, Riggio, Rizzolatti, \& Umiltà, 1987; Hodgson \& Müller, 1995). ${ }^{5}$ One way to reconcile the present data with these findings may be to suggest that the (present) advantage for objects in the upper part of the field simply reflects a left-to-right preferential direction of tracking. That is, the upper-field advantage is coincidental, arising from the fact that the box moving from left to right rotated through the upper part of the field (clockwise rotation).

This was investigated in Experiment 4 by simply reversing the direction of the rotation of the peripheral boxes (i.e., they were rotated counterclockwise). If the upper-box advantage (with clockwise rotation) indeed reflects a preferred left-to-right direction of attentive tracking, it should reverse into a lower-object advantage with counterclockwise rotation. In other words, the advantage should be associated with whatever box moves from left to right.

Note that, in Experiment 4, subject's eye position was monitored. Although IOR (in stationary displays) is known to be unaffected by eye movements (e.g., Posner \& Cohen, 1984), the preference for one of the two moving boxes may reflect strategic eye movements.

\section{Method}

Subjects. Eight subjects ( 5 males and 3 females, with ages ranging from 18 to 37 years) participated in Experiment 4. They all had normal or corrected-to-normal vision. All subjects were right-handed.

Apparatus. Eye position was monitored using a limbus tracker device (Skalar IRIS), interfaced with the LSI-11/23 computer. Eyetracker samples were analyzed at the end of a trial. If a saccade (or drift) greater than $1.5^{\circ}$ was detected (before the manual response), the trial was rejected and rerun later in the block. The percentage of trials rejected due to eye-movement errors was less than $1 \%$ on average (with no subject making more than $2 \%$ errors).

Procedure. The procedure was the same as that in Experiment 3 except for the following differences. The type of motion was fixed (120 steps per full rotation), and the direction of rotation was counterclockwise. Each subject completed 2,400 trials in the moving condition (there was also a stationary control condition, which is presented below as Experiment 5).

Eye fixation was monitored during either the first and third or the second and fourth quarter of the experiment (counterbalanced across 
subjects). An ANOVA of the RT data, with the factors eye fixation monitored/not monitored, cue position, target position, and SOA, failed to reveal any significant effects of the eye movement recording. The eye-fixation factor was therefore dropped from the analyses reported below. The absence of any differences due to this factor suggests that the instruction, together with the high percentage of central targets, provided sufficient incentives for the subjects to maintain fixation at the display center.

\section{Results}

RTs. Table 7 lists the group mean RTs, across SOA, for targets at central, cued, and uncued positions, separately for left and right cues (cue position $\times$ target position $\times$ SOA interaction). Figure 6 illustrates the corresponding patterns of facilitation/inhibition across SOA. The most important result was that the upper-box advantage with clockwise motion (Experiments 1-3) reversed into a lower-box advantage with counterclockwise motion.

The RT data were examined by a repeated measures ANOVA, with main terms for cue position, target position, and SOA. Significant main effects and interactions are listed in Table 8.

At 100 -msec SOAs, cued boxes exhibited facilitation (irrespective of the position of the cue). At longer SOAs, RTs were faster to targets in the right position than to targets in the left position, and, most importantly, RTs were faster to targets in the lower position than to targets in the upper position. In other words, there was a reversal of the upper-position advantage with clockwise rotation (Experiments 1-3) into a lower-position advantage (with counterclockwise rotation) - that is, the advantage remained associated with whatever box moved from left to right. Thus, there is a preference to attentively track the left-to-right moving object irrespective of the direction of rotation. Attentive tracking is covert, not dependent on strategic eye movements.

As in Experiment 3, there was no evidence of dynamic, object-centered IOR (at SOAs longer than $500 \mathrm{msec}$ ); rather, any inhibition manifest at those SOAs was associated with the upper and left positions, irrespective of whether the cued or uncued box happened to occupy those positions.

Table 7

Mean Reaction Times and Facilitation/Inhibition (in Milliseconds) in Experiment 4

\begin{tabular}{lccccc}
\hline & \multicolumn{5}{c}{ SOA (in milliseconds) } \\
\cline { 2 - 6 } \multicolumn{1}{c}{ Cue } & 100 & 400 & 700 & 1,000 & 1,300 \\
\hline Left & & & & & \\
$\quad$ Central & 359 & 327 & 313 & 303 & 262 \\
$\quad$ Cued & $359_{\mathrm{l}}$ & $405_{\mathrm{b}}$ & $375_{\mathrm{r}}$ & $380_{\mathrm{t}}$ & $298_{\mathrm{l}}$ \\
$\quad$ Uncued & $386_{\mathrm{r}}$ & $435_{\mathrm{t}}$ & $391_{\mathrm{l}}$ & $362_{\mathrm{b}}$ & $283_{\mathrm{r}}$ \\
$\quad$ Facilitation/Inhibition & $+27^{*}$ & $+30^{*}$ & +16 & -18 & -15 \\
Right & & & & & \\
$\quad$ Central & 366 & 328 & 320 & 305 & 262 \\
$\quad$ Cued & $363_{\mathrm{r}}$ & $431_{\mathrm{t}}$ & $394_{\mathrm{I}}$ & $364_{\mathrm{b}}$ & $287_{\mathrm{r}}$ \\
$\quad$ Uncued & $384_{\mathrm{l}}$ & $398_{\mathrm{b}}$ & $380_{\mathrm{r}}$ & $377_{\mathrm{t}}$ & $295_{\mathrm{l}}$ \\
$\quad$ Facilitation/Inhibition & $+24^{*}$ & $-33^{*}$ & -14 & +13 & +8 \\
\hline
\end{tabular}

Note $-\mathrm{l}=$ left position; $\mathrm{r}=$ right position; $\mathrm{t}=$ top position; $\mathrm{b}=$ bottom position. + indicates facilitation; - indicates inhibition. *Significant, $\alpha=.05$.
Errors. Anticipation and catch-trial errors were rare overall (less than $1 \%$ on average, with no subject above $2.5 \%$ ). An ANOVA of the arcsine-transformed anticipation rates, with the factors cue position, target position, and SOA, failed to reveal any significant effects. However, anticipations tended to be made only at longer SOAs $(<400 \mathrm{msec})$.

\section{Discussion}

One explanation of the left-to-right tracking bias may be found in the acquisition of skilled reading, which involves a left-to-right direction of visual scanning. Work on the "perceptual span" in reading by Rayner and his colleagues (e.g., McConkie \& Rayner, 1976; Rayner \& Bertera, 1979) has shown that, for English readers, the span is asymmetrically extended toward the right of the fixation point and that this asymmetry increases with reading skill. Interestingly, the asymmetry is reversed for readers of languages (e.g., Hebrew) that are written from right to left (Pollatsek, Bolozky, Well, \& Rayner, 1981), suggesting that attentional left-right biases are "learned."

It is not clear, however, whether the right-side advantage found in the present experiments is indeed caused by preferential scanning direction. One possible alternative is provided by the hand used for response (e.g., Possamai,, 1991). In the present experiments, all subjects were righthanded and responded with their preferred hand. It is well known that right-hand responses are faster to stimuli on the right and that left-hand responses are faster to stimuli on the left (spatial stimulus-response compatibility; e.g., Simon, Sly, \& Vilapakkam, 1981). However, unlike the standard Simon paradigm, the present experiments did not require a choice of response (left or right hand) but only a simple manual RT. Nevertheless, execution of even a simple manual response might involve (at least rudimentary) directional programming (i.e., preparation of a directed movement to the target object; see Crawford \& Müller, 1992, and Hodgson, Müller, \& O'Leary, 1995, for a similar argument). Consequently, objects to the right would naturally attract a right-hand response, producing rightside facilitation even with simple manual RTs.

\section{EXPERIMENT 5}

In addition to providing a static control condition to Experiments 3, 4, and 6, Experiment 5 was designed to reinvestigate the role of the response-hand in left-right biases. Experiment 5 presented stationary displays. Peripheral cues were spatially informative at the $100-\mathrm{msec}$ SOA but were uninformative at the $1,300-\mathrm{msec}$ SOA (the only SOA after the center flash that occurred $500 \mathrm{msec}$ after cue onset). The subjects responded with either the left or the right hand (simple manual RT) in separate blocks of trials.

The variation of response hand in Experiment 5 is similar to that used by Possamaï (1991). Possamaï observed early facilitation (RT advantage for cued positions relative to uncued positions) only when cued side and response hand were corresponding (e.g., right cue and right-hand response), not when they were crossed (e.g., left cue and 


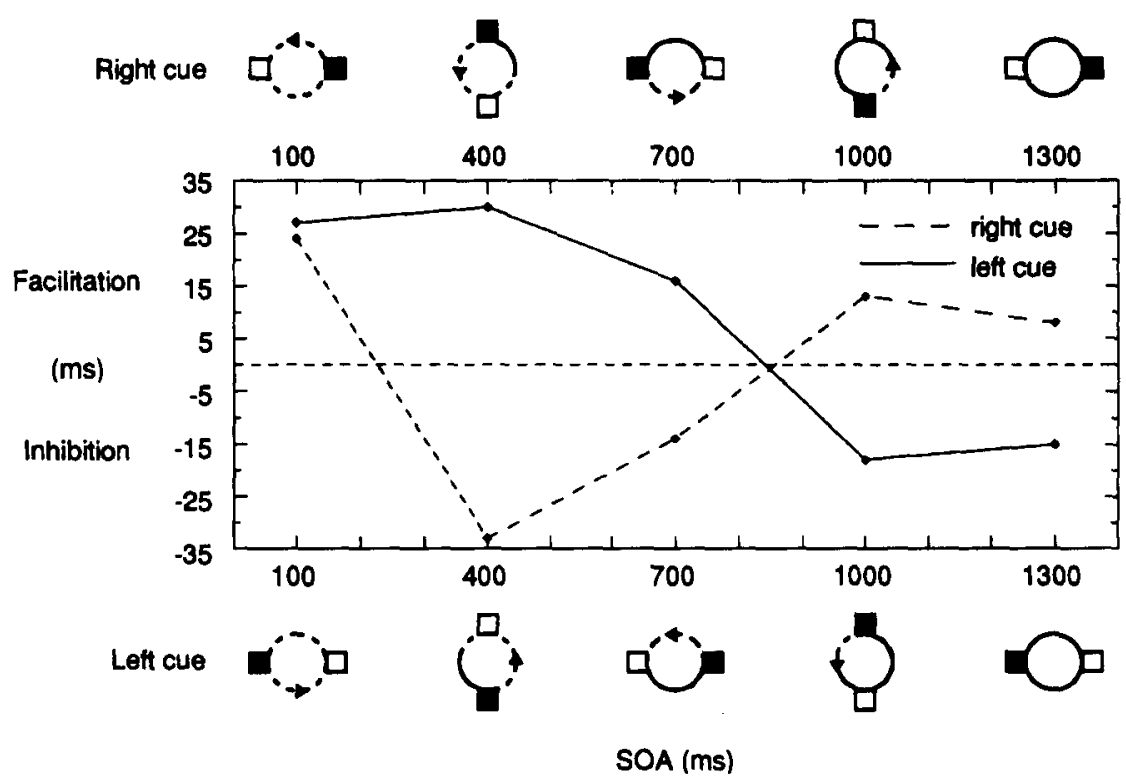

Figure 6. Mean reaction time facilitation/inhibition as a function of cue-target SOA, separately for left- and right-side cues. The icons along the $x$-axis indicate the positions of the cued (filled) and uncued (unfilled) boxes at the respective SOA.

right-hand response) (14 vs. $-15 \mathrm{msec}) .{ }^{6}$ Conversely, there was reliable late inhibition (RT disadvantage for cued positions relative to uncued positions) only with crossed, not corresponding, cue-hand relationships ( -33 vs. -5 msec; see Note 6). However, the slowing of RTs to cued-position targets relative to uncued-position targets across SOA was comparable for both types of relationship [crossed, $(+14)-(-5)=19 \mathrm{msec}$; corresponding, $(-15)-$ $(-33)=18 \mathrm{msec}$; see Note 6]. Possamaï argued from this that early facilitation reflected Simon-type "response priming" of the hand ipsilateral to the cue. The later inhibition (i.e., relative slowing of cued-target RTs) was due to a perceptual aftereffect of the cue and/or suppression in the motor system arising from the need to withhold a response to the cue and wait for the target. Both of these factors would affect ipsilateral and contralateral hand responses equally.

Note, however, that the cues used by Possamaï were spatially uninformative (and not followed by a central flash), so that it is not clear what role the spatial orienting of attention played for his results. Therefore, Experiment 5 examined whether a pattern of effects similar to Possamaï's would also be obtained when spatially informative cues are used to orient attention to the periphery.

\section{Method}

Subjects. Sixteen subjects ( 10 males and 6 females, with ages ranging from 18 to 38 years) participated in Experiment 5. They all had normal or corrected-to-normal vision. All subjects were right-handed (as assessed by Edinburgh Inventory; Oldfield, 1971). Note that the data of 2 subjects could not be analyzed due to a hard-disk failure.

Procedure. The procedure was the same as that in the stationary condition of Experiment 2. Cues could appear either left or right, followed by a target in the cued or the uncued box at $100-$ or $1,300-\mathrm{msec}$ SOA. The subjects responded with either the left hand or the right hand in separate blocks of trials. Experiment 5 was conducted concurrently with Experiments 3, 4, and 6, serving as stationary control for the moving conditions in those experiments. In each session, the subjects started with a stationary condition, followed by a moving condition (Experiments 3, 4, and 6), followed by a stationary condition. The response hand (left or right) used in the first and second stationary conditions was counterbalanced across sessions and subjects.

\section{Results}

RTs. Table 9 presents the group mean RTs, across SOA, for targets at central, cued, and uncued positions, separately for left and right cues (response hand $\times$ cue position $\times$ target position $\times$ SOA interaction). Figure 7 illustrates the corresponding patterns of facilitation/inhibition, which showed a tendency for IOR to be more marked for crossed cue-hand relationships.

The RT data were examined by a repeated measures ANOVA, with main terms for response hand, cue position, target position, and SOA. Significant main effects and interactions are listed in Table 10.

Most importantly, the target position $\times$ SOA interaction was significant. This was due to cued positions showing fa-

Table 8

Summary of Reaction Time Analysis of Variance Effects in Experiment 4

\begin{tabular}{lrrrr}
\multicolumn{1}{r}{ Effect } & $F$ & $d f$ & $M S_{\mathrm{e}}$ & $p$ \\
\hline Main Effects & & & & \\
TP & 38.96 & 2,14 & $1,940.34$ & .001 \\
SOA & 49.86 & 4,28 & $1,606.45$ & .001 \\
Interactions & & & & \\
TP $\times$ SOA & 10.56 & 8,56 & 564.14 & .001 \\
CP $\times$ TP $\times$ SOA & 1.84 & 8,56 & 833.12 & .100 \\
\hline
\end{tabular}

Note $-\mathrm{CP}=$ cued position; $\mathrm{TP}=$ target position; $\mathrm{SOA}=$ stimulus onset asynchrony. 
Table 9

Mean Reaction Times and Facilitation/Inhibition (in Milliseconds) in Experiment 5

\begin{tabular}{|c|c|c|c|c|}
\hline \multirow[b]{3}{*}{ Cue } & \multicolumn{2}{|c|}{ Left Hand } & \multicolumn{2}{|c|}{ Right Hand } \\
\hline & \multicolumn{2}{|c|}{ SOA (in milliseconds) } & \multicolumn{2}{|c|}{ SOA (in milliseconds) } \\
\hline & 100 & 1,300 & 100 & 1,300 \\
\hline \multicolumn{5}{|l|}{ Left } \\
\hline Central & 362 & 314 & 353 & 310 \\
\hline Cued & $362_{1}$ & $328_{1}$ & $356_{1}$ & $325_{1}$ \\
\hline Uncued & $386_{\mathrm{r}}$ & $320_{\mathrm{r}}$ & $385_{r}$ & $303_{r}$ \\
\hline Facilitation/Inhibition & $+24^{*}$ & -8 & $+29^{*}$ & $-22^{*}$ \\
\hline \multicolumn{5}{|l|}{ Right } \\
\hline Central & 361 & 313 & 358 & 312 \\
\hline Cued & $375_{r}$ & $336_{\mathrm{r}}$ & $368_{r}$ & $324_{\mathrm{r}}$ \\
\hline Uncued & $402_{1}$ & $312_{1}$ & $392_{1}$ & $309_{1}$ \\
\hline Facilitation/Inhibition & $+27^{*}$ & $-24^{*}$ & $+24^{*}$ & $-15^{*}$ \\
\hline
\end{tabular}

cilitation relative to uncued positions at the 100 -msec SOA but showing inhibition at the $1,300-\mathrm{msec}$ SOA. The fourway interaction (illustrated in Figure 7) approached significance. While the magnitude of the facilitation showed little effect of the relationship between response hand and cue position (corresponding, $24 \mathrm{msec}$; crossed, $28 \mathrm{msec}$ ), the IOR effect tended to be larger with crossed relationships than with corresponding relationships ( $-23 \mathrm{vs} .-12 \mathrm{msec})$.

Errors. Anticipation and catch-trial errors were rare overall (less than $1 \%$ on average, with no subject above
$2 \%$ ). An ANOVA of the arcsine-transformed anticipation rates, with the factors response hand, cue position, target position, and SOA, failed to reveal any significant effects. However, anticipations tended to be made only at the 1,300-msec SOAs.

\section{Discussion}

In summary, the results of Experiment 5 suggest that early facilitation produced by spatially informative peripheral cues is unaffected by the relationship between re-
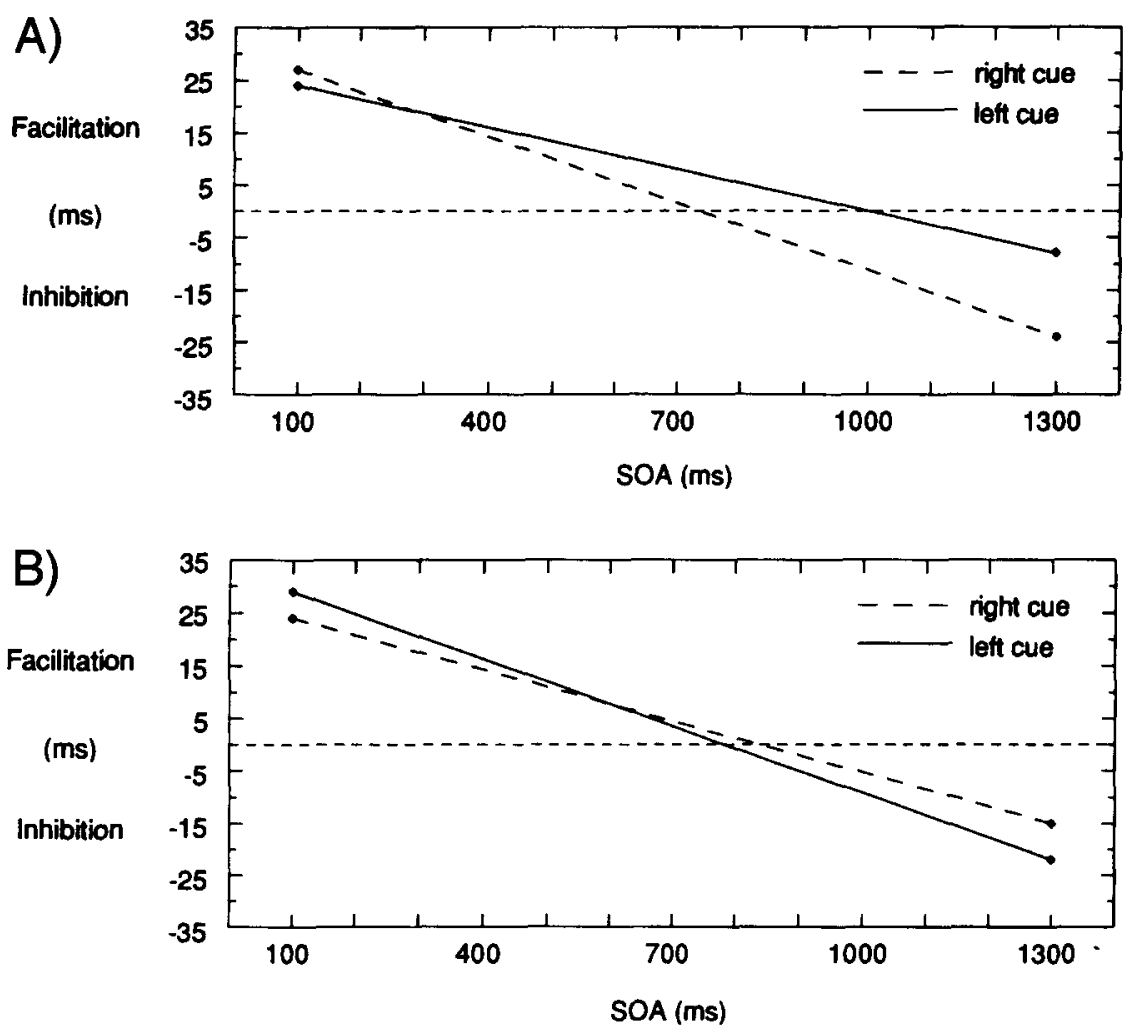

Figure 7. Mean reaction time facilitation/inhibition as a function of cue-target SOA, separately for left- and right-side cues with $(A)$ left-hand responses and $(B)$ right-hand responses. 
Table 10

Summary of Reaction Time Analysis of Variance Effects in Experiment 5

\begin{tabular}{lrrrr}
\multicolumn{1}{c}{ Effect } & $F$ & $d f$ & $M S_{\mathrm{e}}$ & $p$ \\
\hline Main Effects & & & & \\
$\quad$ CP & 5.84 & 1,13 & 330.40 & .05 \\
TP & 18.15 & 2,26 & 421.00 & .001 \\
SOA & 59.08 & 1,13 & $4,196.10$ & .001 \\
Interactions & & & & \\
TP $\times$ SOA & 31.54 & 2,26 & 469.17 & .001 \\
RH $\times$ CP $\times$ TP $\times$ SOA & 2.79 & 2,26 & 182.40 & .100 \\
\hline
\end{tabular}

Note $-\mathrm{RH}=$ response hand $\mathrm{CP}=$ cued position; $\mathrm{TP}=$ target position; $\mathrm{SOA}=$ stimulus onset asynchrony.

sponse hand and cue position, in contrast to uninformative cues, which produce a Simon-type motor preference for targets on the same side as the response hand (Possamai,, 1991). Assuming that such a preference is the norm, why did it not affect the early facilitation in Experiment 5? Two accounts are usually put forward to explain the facilitatory effects of spatial cues on simple RTs: enhanced perceptual (attentive) processing at the cued location and/or a motor bias (i.e., priming of a response to a target at the cued location). If detection of a target in the cued box is enhanced (i.e., if it is detected earlier than is a target in the uncued box), there would be a time gain in connecting a cued-box target to the simple manual response. But if that connection can be made faster when a cued-box target appears on the side of the response hand (e.g., due to even a simple manual reaction involving programming of a directed response to the target), facilitation should be larger for corresponding cue-hand relationships, which is at odds with the present data. Thus, "perceptual enhancement" cannot explain why the general preference for responding to a lateral target with the ipsilateral hand was abolished by the informative cues in Experiment 5. "Motor bias," by contrast, could offer a plausible account. A motor bias induced by the cue would connect any manual response, whether with the left or the right hand, directly to the cued box in advance of a target appearing there. In other words, at the 100-msec SOA, the cue would have primed any hand, doing away with the need to link the target to the response after its appearance. This need would normally (in the absence of a motor bias) produce a Simon-type stimulus-response compatibility effect.

In contrast to the early facilitation, the relationship between response hand and cue position affects the magnitude of the later IOR effect: IOR tends to be reduced to targets on the same side as the hand used for response, no matter whether cues are spatially informative (Experiment 5) or uninformative (Possamaï, 1991). The (re-)appearance of the cue-hand relationship at the long SOA could be explained if the motor bias was abolished by that time, due to the cue being no longer informative after the central flash, and the target had to be connected to the response after its appearance (by a system that had reverted to its Simon-type default mode). The prolonged RTs to cued-box targets at the long SOA (the IOR effect) might then have two causes. It could result from perceptual in- hibition at the cued location (delaying the detection of a cued-box target), which would affect ipsilateral and contralateral hand responses equally. Alternatively, it could arise as an aftereffect of having to suppress a response to the cue (inhibiting a subsequent cued-box target to be linked to response), which would also affect ipsilateral and contralateral hand responses equally.

Experiment 5 was not designed to distinguish between these alternatives. However, it (as well as the experiment of Possamai, 1991) shows that the pattern of early facilitation and later IOR cannot be adequately explained without recourse to response mechanisms and that a purely response-based account of these effects is feasible in principle. The arguments for such an account are strengthened by evidence from other studies suggesting that IOR is not perceptual in nature (see the General Discussion for a more detailed consideration of this point).

\section{EXPERIMENT 6}

Experiments $6 \mathrm{~A}$ and $6 \mathrm{~B}$ examined further methodological differences between the present experiments and those of Tipper et al. (1991). One difference concerns the SOA between peripheral cue and central flash: $500 \mathrm{msec}$ in the present experiments and $200 \mathrm{msec}$ in the experiments of Tipper et al. The other difference concerns the presentation of the target: In the experiments of Tipper et al., the exposure of the target was brief $(67 \mathrm{msec})$ and disrupted the motion of the peripheral boxes; in the present experiments, the target was displayed until response, moving continuously inside its box.

It could be that the long SOA between peripheral cue and central flash in the present experiments allowed attentive tracking of the left-to-right moving box to be established. As a result, dynamic, object-centered IOR may have been obscured by active attention to one of the two boxes (see Posner \& Cohen, 1984).

Alternatively, the disruption of the motion of the tracked box (the upper box with clockwise rotation) when the target was presented in the experiments of Tipper et al. may have led to attentional "overshoot." That is, a target in the tracked box would appear outside the focus of attention, affecting RT to that target (e.g., because an attentional reversal correcting the overshoot is necessary for response; see Rizzolatti, Riggio, Dascola, \& Umiltà, 1987). Note that losing track of the attended box would not necessarily affect RT to a target in the untracked box (e.g., because, whether or not box motion is disrupted, attention would have to be switched from the tracked box to the nontracked box).

These alternatives were tested in Experiments 6A and 6B. In both experiments, the central flash appeared $200 \mathrm{msec}$ after the peripheral cue onset. There were three SOAs: 100 , 400 , or $700 \mathrm{msec}$ (which means that the peripheral boxes reached their terminal positions after a $180^{\circ}$ rotation). The direction of rotation was clockwise. In all other respects, Experiment 6A was the same as the previous experimentsin particular, the target remained on until response, moving continuously with the peripheral box containing it. In 
contrast, in Experiment 6B, the target was only briefly presented (for $70 \mathrm{msec}$ ), and the rotation of the peripheral boxes was interrupted during target exposure, similar to the experiments of Tipper et al. (1991).

If a short interval between peripheral cue and central flash is important to observing dynamic, object-centered IOR, the effect should become manifest in Experiment $6 \mathrm{~A}$. However, if the interruption of the box motion during target presentation is important, dynamic, object-centered IOR should be observed in Experiment 6B.

\section{Method}

Subjects. Ten subjects ( 6 males and 4 females, with ages ranging from 18 to 32 years) participated in Experiments 6A and 6B. They all had normal or corrected-to-normal vision. All subjects were right-handed. They were paid $£ 4.00$ per hour.

Procedure. The procedure was the same as that used previously except for the following differences. The central flash appeared $200 \mathrm{msec}$ after the peripheral cue onset, there were only three SOAs $(100,400$, or $700 \mathrm{msec}$; i.e., a semicircular rotation), and the direction of rotation was always clockwise. In both experiments, the motion of the boxes was smooth (i.e., 120/2 displacements per semicircle). In Experiment $6 \mathrm{~A}$, the target, when it appeared, moved continuously with the box that contained it and remained on until response. In contrast, in Experiment $6 \mathrm{~B}$, the target was presented for $70 \mathrm{msec}$ in the $0^{\circ}, 90^{\circ}, 180^{\circ}$, or $270^{\circ}$ position, during which time the box motion was interrupted. Each experiment consisted of 1,440 trials [ 2 cue position $\times 3$ SOA $\times(50$ cued +50 uncued +100 central target trials) +240 catch trials], which were presented in two sessions. The order of experiments was counterbalanced across subjects.

There was also a stationary control condition, which was presented above as Experiment 5 .

\section{Results}

RTs. Table 11 presents the group mean RTs, across SOA, for targets at central, cued, and uncued positions, separately for left and right cues. Figure 8 illustrates the corresponding patterns of facilitation/inhibition across SOA.

The RT data were examined by a repeated measures ANOVA, with main terms for experiment (6A/6B), cue position, target position, and SOA. Significant main effects and interactions are listed in Table 12.

The RTs were faster with left-side cues (3-msec advantage; main effect of cue position), central targets ( $30-\mathrm{msec}$ advantage; main effect of target position), and longer SOAs (main effect of SOA). The main effect of experiment was not significant $[F(1,9)=0.10]$, nor were there any significant interactions involving experiment.

The most interesting interaction was cue position $x$ target position $\times$ SOA. With left-side cues, there tended to be facilitation for cued locations at all SOAs (combined across Experiments $6 \mathrm{~A}$ and $6 \mathrm{~B}$ ). With right-side cues, there was marked facilitation at the 100-msec SOA and inhibition at the 700-msec SOA.

The four-way interaction was not significant $[F(4,26)=$ $1.85]$, although inspection of facilitation/inhibition at the 400 -msec SOA suggests a differential pattern between the experiments (see Table 11 and Figure 8). In Experiment 6A, which was similar to the previous experiments, there was facilitation for the cued box $(10 \mathrm{msec})$ with left-side cues (target in upper position) and inhibition $(-7 \mathrm{msec})$ with right-side cues (target in lower position). This pattern agrees with that of the previous experiments, although the advantages for the upper box over the lower box appear somewhat reduced. Thus, the earlier onset of the central flash (200-msec SOA) did not (or not completely) prevent attentive tracking of the left-to-right moving box.

In Experiment 6B, which was similar to the experiments of Tipper et al. (1991), the pattern of facilitation/inhibition at the 400 -msec SOA appears reversed. With left-side cues, there was a nonsignificant disadvantage $(-5 \mathrm{msec})$ for the cued box in the upper position relative to the uncued box in the lower position. With right-side cues, there was a nonsignificant advantage $(3 \mathrm{msec})$ for the cued box in the lower position relative to the uncued box in the upper position. Restated, there tended to be an advantage for the lower box over the upper box, reversing the advantage for the upper box over the lower box observed in Experiment 6A.

Note that the RTs for the lower position did not differ between Experiments 6A and 6B. An ANOVA of the lower position RTs at the 400-msec SOA, with main terms for experiment and target position (cued/uncued box), failed to reveal any significant effects (similarly, central position RTs did not differ between the experiments). In other words, the upper-box advantage in Experiment $6 \mathrm{~A}$ and the

Table 11

Mean Reaction Times and Facilitation/Inhibition (in Milliseconds) in Experiment 6

\begin{tabular}{|c|c|c|c|c|c|c|}
\hline \multirow[b]{3}{*}{ Cue } & \multicolumn{3}{|c|}{ Experiment $6 \mathrm{~A}$} & \multicolumn{3}{|c|}{ Experiment $6 \mathrm{~B}$} \\
\hline & \multicolumn{3}{|c|}{ SOA (in milliseconds) } & \multicolumn{3}{|c|}{ SOA (in milliseconds) } \\
\hline & 100 & 400 & 700 & 100 & 400 & 700 \\
\hline \multicolumn{7}{|l|}{$\overline{\text { Left }}$} \\
\hline Central & 355 & 290 & 227 & 353 & 292 & 232 \\
\hline Cued & $363_{1}$ & 322, & $261_{\mathrm{r}}$ & $354_{1}$ & $343_{\mathrm{t}}$ & $256_{\tau}$ \\
\hline Uncued & $369_{\mathrm{r}}$ & $332_{b}$ & $267_{1}$ & $363 r$ & $338_{\mathrm{b}}$ & $266_{1}$ \\
\hline Facilitation/Inhibition & +6 & $+10^{*}$ & +6 & $+9 *$ & -5 & $+10^{*}$ \\
\hline \multicolumn{7}{|l|}{ Right } \\
\hline Central & 359 & 293 & 236 & 357 & 284 & 234 \\
\hline Cued & $355_{\mathrm{r}}$ & $335_{b}$ & $275_{1}$ & $360_{r}$ & $334_{b}$ & $277_{1}$ \\
\hline Uncued & $381_{1}$ & $328_{t}$ & $257_{\mathrm{r}}$ & $391_{1}$ & $337_{t}$ & $258_{\mathrm{r}}$ \\
\hline Facilitation/Inhibition & $+26^{*}$ & $-7^{*}$ & $-18^{*}$ & $+31^{*}$ & +3 & $-19 *$ \\
\hline
\end{tabular}



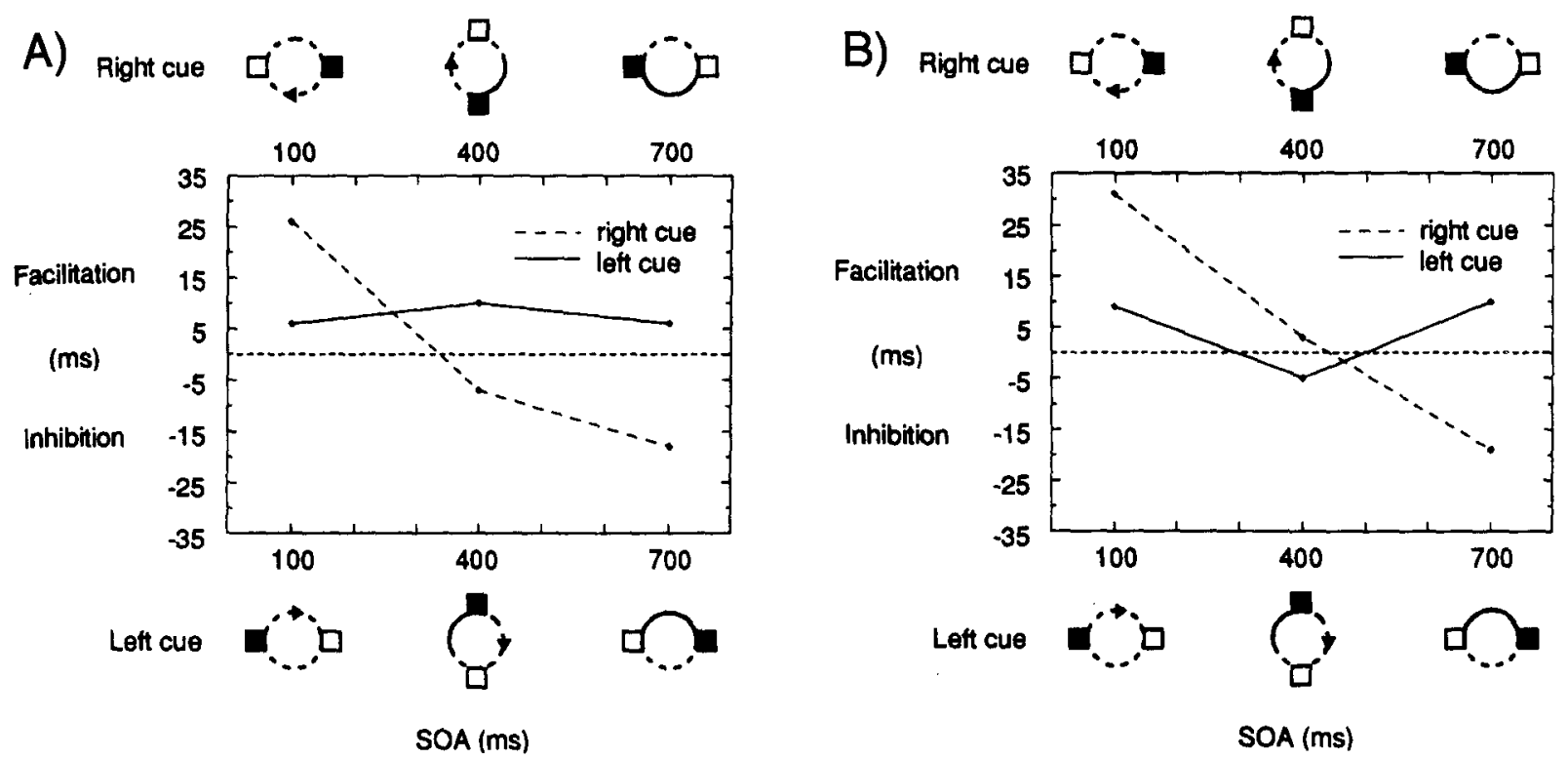

Figure 8. Mean reaction time facilitation/inhibition as a function of cue-target SOA, separately for left- and right-side cues in (A) Experiment $6 \mathrm{~A}$ and (B) Experiment 6B. The icons along the $x$-axis indicate the positions of the cued (filled) and uncued (unfilled) boxes at the respective $\mathrm{SOA}$.

upper-box disadvantage in Experiment $6 \mathrm{~B}$ were due to a specific advantage ( $9 \mathrm{msec}$ ) and, respectively, disadvantage $(-4 \mathrm{msec})$ for the upper position.

Errors. Anticipation and catch-trial errors were rare overall (less than $1 \%$ on average, with no subject above $2 \%$ ). An ANOVA of the arcsine-transformed anticipation rates, with the factors experiment, cue position, target position, and SOA, failed to reveal any significant effects. However, anticipations tended to be made only at the 700msec SOAs.

\section{Discussion}

In summary, it is unlikely that the SOA between the peripheral cue and the central flash (which is presented to summon attention to the center) is critical for dynamic, object-centered IOR to occur. In Experiment 6A, the familiar pattern of an advantage of the upper box over the lower box was observed at the 400 -msec SOA (though this seemed reduced in comparison with the previous experiments), suggesting attentive tracking of the left-to-right moving box. A pattern looking anything like dynamic, object-centered IOR was observed only in Experiment 6B, with left-side cues, at the 400-msec SOA, with the cued box in the upper position showing some (nonsignificant) inhibition. However, the most likely explanation for this pattern is to be found in the attentive-tracking account outlined above. The box moving from left to right (which, with left-side cues, happened to be the cued box) is tracked (see Experiment 6A). However, the disruption of the box motion when the target is exposed may lead to attentional overshoot. That is, the target in the tracked box would appear outside the focus of attention, affecting RT to that target, perhiaps due to a bias against returning attention to a position scanned only recently. Such a bias would leave
RTs to targets in the untracked box relatively unaffected. If data from only left-side cues are considered, such a pattern of facilitation/inhibition could be mistaken for dynamic, object-centered IOR.

Note that, according to the attentive-tracking account, no differential performance between Experiments 6A and 6B would necessarily be expected at the $700-\mathrm{msec}$ SOA because, at that time, the box motion had terminated. Since the end positions of the box motions were entirely predictable (semicircular rotation), the attentive-tracking account would not predict an overshoot (i.e., box motion would not be unpredictably disrupted in the brief-exposure condition of Experiment $6 \mathrm{~B}$ ). Overshoot would only be expected at the $400-\mathrm{msec}$ SOA because it would not be predictable whether or not the box motion would be interrupted and a target would be presented at that time (in fact, it was most likely that it would not). It is interesting to note that Tipper et al. (1994) found no consistent evidence for dynamic, object-centered IOR when the cued box rotated

Table 12

Summary of Reaction Time Analysis of Variance Effects in Experiment 6

\begin{tabular}{lrlrl}
\multicolumn{1}{c}{ Effect } & $F$ & $d f$ & $M S_{\mathrm{e}}$ & \multicolumn{1}{c}{$p$} \\
\hline Main Effects & & & & \\
CP & 13.40 & 1,9 & 40.67 & .01 \\
TP & 118.87 & 2,18 & 302.49 & .001 \\
SOA & 120.93 & 2,18 & $3,103.41$ & .001 \\
Interactions & & & & \\
CP $\times$ SOA & 6.60 & 2,18 & 27.39 & .01 \\
TP $\times$ SOA & 19.19 & 4,36 & 242.85 & .001 \\
CP $\times$ TP $\times$ SOA & 9.20 & 4,36 & 154.25 & .001 \\
\hline
\end{tabular}

Note $-\mathrm{CP}=$ cued position; $\mathrm{TP}=$ target position; $\mathrm{SOA}=$ stimulus onset asynchrony. 
only $180^{\circ}$ (i.e., at SOAs around $700 \mathrm{msec}$ ), in contrast to Tipper et al. (1991).

\section{EXPERIMENT 7}

Experiments 7A and 7B examined two further methodological differences between the present experiments and those of Tipper et al. (1991). In the previous experiments, the box motion commenced $100 \mathrm{msec}$ after peripheral cue onset, before the onset of the central flash (at 200- or 500msec SOAs); a target could appear at the $100-\mathrm{msec}$ SOA. In contrast, in the study of Tipper et al., the start of the box motion coincided with the onset of the central flash (200-msec SOA), and no targets were presented before that time. The earlier onset of the box motion in the present experiments, together with the possibility of an earlier target occurring, may have induced attentive tracking, which, in turn, may have masked dynamic, object-centered IOR. ${ }^{7}$ Therefore, Experiments 7A and 7B examined whether dynamic, object-centered IOR would be observed when the onset of the box motion and the central flash occur at the same time and/or when no targets are presented before that time. The SOA between peripheral cue and central flash/box motion onset was $200 \mathrm{msec}$ in Experiments 7A and 7B (as in Tipper et al., 1991). The difference between the two experiments was whether or not a target could occur before the central flash/box motion onset (cue-target SOAs: 100,500 , or $800 \mathrm{msec}$ in Experiment $7 \mathrm{~A} ; 500$ or $800 \mathrm{msec}$ in Experiments 7B). A target, once presented, stayed on and moved continuously inside its box until response. This was done to preclude the possibility of artifactual IOR produced by target exposure during unpredictable pauses of the box motion (see Experiment 6B); furthermore, objects in the real world tend to move continuously without stopping to display a critical "target" signal.

One further variable investigated in Experiment 7 was the response hand. Experiment 5 had shown that IOR in stationary displays is dependent on the response hand: IOR tended to be stronger for crossed cue-hand relationships than for corresponding cue-hand relationships. Experiment 7 asked whether attentive tracking in dynamic displays (if not abolished by the above changes to the display parameters) would also be affected by response hand. Specifically, the tendency in the previous experiments to track the object that moved from left to right may have been induced by the use of the right hand to respond. If even a simple manual response to an object involves programming of a directed response, and if the right hand is better suited to intercept an object moving from the left to the right, this could explain (or at least contribute) the left-to-right tracking preference. Accordingly, this preference should be reversed (or at least diminished) when subjects use the left hand to respond. There is evidence for the idea that the particular motor system used for response influences the allocation of visual attention. For example, left visual neglect patients may show reductions in neglect with active left-hand movements in the left hemifield (e.g., Halligan \& Marshall, 1989; Joanette, Brouchon, Gauthier,
\& Samson, 1986; Robertson \& North, 1993; see also Rizzolatti \& Gallese, 1988). By varying response hand, Experiment 7 was designed to extend this idea to the interaction with dynamic displays.

\section{Method}

Subjects. Ten subjects ( 7 males and 3 females, with ages ranging from 18 to 38 years) participated in Experiments 7A and 7B. They all had normal or corrected-to-normal vision. All subjects were right-handed (as assessed by Edinburgh Inventory; Oldfield, 1971). They were paid $£ 4.00$ per hour.

Apparatus. Stimuli were presented on a Tektronix $608 \mathrm{X}-\mathrm{Y}$ monitor with a (very fast decay) $\mathrm{P} 15$ phosphor. The monitor was driven by a Dell $433 / \mathrm{M}$ computer by way of an Interactive Electronics Systems oscilloscopic point plotter (Finley, 1985). The subjects responded by pressing the left or right button of the Microsoft mouse placed in front of them. All other technical details were the same as in the previous experiments.

Procedure. The procedure was the same as that used previously except for the following differences. The box motion (in clockwise direction) started $200 \mathrm{msec}$ after the peripheral cue onset, coinciding with the onset of the central flash. The cue-target SOAs were 100,500 , or $800 \mathrm{msec}$ in Experiment $7 \mathrm{~A}$ and 500 or $800 \mathrm{msec}$ in Experiment $7 \mathrm{~B}$. Central targets were not presented. In both experiments, the motion of the boxes was smooth (i.e., 120/2 displacements per semicircle). Experiment $7 \mathrm{~A}$ consisted of 1,440 trials [2 response hand $\times 2$ cue position $\times 3$ SOA $\times(50$ cued +50 uncued $)+240$ catch trials]; Experiment $7 \mathrm{~B}$ consisted of 960 trials [ 2 response hand $\times 2$ cue position $\times 2$ SOA $\times(50$ cued +50 uncued $)+160$ catch trials]. The subjects performed 720 Experiment $7 \mathrm{~A}$ trials and $480 \mathrm{Ex}-$ periment $7 \mathrm{~B}$ trials in each of the two sessions, with the order of experiment counterbalanced across subjects. Within a session, the subjects responded with either the left hand or the right hand, with the order of response hand counterbalanced across sessions. The subjects were informed at the beginning of each experimental ( $7 \mathrm{~A}$ or 7B) block of trials whether or not to expect any targets before the central flash onset (i.e., 100-msec SOA).

\section{Results}

RTs. Table 13 presents the group mean RTs, across SOA, for targets at cued and uncued positions, separately for left and right cues and for left and right hand responses; the data for the 500- and 800-msec SOAs were combined across Experiments 7A and 7B (because there were no significant differences between the experiments; see below). Figure 9 illustrates the corresponding patterns of facilitation/inhibition across SOA.

The RT data were examined initially by a repeated measures ANOVA, with main terms for experiment (7A or $7 \mathrm{~B}$ ), response hand, cue position, target position, and SOA (500 or $800 \mathrm{msec}$; the 100 -msec SOA data of Experiment 7A were ignored in this analysis). Importantly, there were no significant effects involving experiment. This indicates that responses, at $500-$ and $800-\mathrm{msec}$ SOAs, were unaffected by whether or not a target could be presented before the box motion and central flash onsets.

Since there were no differences between Experiments $7 \mathrm{~A}$ and $7 \mathrm{~B}$ at the 500- and $800-\mathrm{msec}$ SOAs, the data were combined and subjected to a repeated measures ANOVA, with main terms for response hand, cue position, target position, and SOA $(100,500$, or $800 \mathrm{msec}$; note that the 100 -msec SOA data of Experiment 7A were included in 
Table 13

Mean Reaction Times and Facilitation/Inhibition (in Milliseconds) in Experiment 7

\begin{tabular}{|c|c|c|c|c|c|c|}
\hline \multirow[b]{3}{*}{ Cue } & \multirow{2}{*}{\multicolumn{3}{|c|}{$\begin{array}{l}\text { Left Hand } \\
\text { SOA (in milliseconds) }\end{array}$}} & \multirow{2}{*}{\multicolumn{3}{|c|}{$\begin{array}{l}\text { Right Hand } \\
\text { SOA (in milliseconds) }\end{array}$}} \\
\hline & & & & & & \\
\hline & 100 & 500 & 800 & 100 & 500 & 800 \\
\hline \multicolumn{7}{|l|}{ Left } \\
\hline $\begin{array}{l}\text { Cued } \\
\text { Uncued }\end{array}$ & $\begin{array}{l}506_{1} \\
519_{r}\end{array}$ & $\begin{array}{l}364_{t} \\
368_{b}\end{array}$ & $\begin{array}{l}367_{r} \\
375_{I}\end{array}$ & $\begin{array}{l}516_{1} \\
525_{r}\end{array}$ & $\begin{array}{l}355_{\mathrm{t}} \\
369_{\mathrm{b}}\end{array}$ & $\begin{array}{l}356_{\mathrm{r}} \\
367_{1}\end{array}$ \\
\hline Facilitation/Inhibition & $+13^{*}$ & +4 & $+8^{*}$ & $+9^{*}$ & $+14^{*}$ & $+11^{*}$ \\
\hline \multicolumn{7}{|l|}{ Right } \\
\hline $\begin{array}{l}\text { Cued } \\
\text { Uncued }\end{array}$ & $\begin{array}{l}518_{\mathrm{r}} \\
522_{1}\end{array}$ & $\begin{array}{l}371_{b} \\
367_{t}\end{array}$ & $\begin{array}{l}368_{I} \\
366_{r}\end{array}$ & $\begin{array}{l}506_{\mathrm{r}} \\
524_{1}\end{array}$ & $\begin{array}{l}366_{b} \\
364_{t}\end{array}$ & $\begin{array}{l}359_{1} \\
359_{r}\end{array}$ \\
\hline Facilitation/Inhibition & +4 & -4 & -2 & $+18^{*}$ & -2 & 0 \\
\hline
\end{tabular}

Note- $1=$ left position; $r=$ right position; $t=$ top position; $b=$ bottom position. + indicates facilitation; - indicates inhibition. * Significant, $\alpha=.05$.

this analysis). Significant main effects and interactions are listed in Table 14.

RTs to targets in cued boxes overall were faster than RTs to targets in uncued boxes (main effect of target position). Furthermore, this advantage for cued box targets was more marked with left-side cues than with right-side cues ( 11 vs. $3 \mathrm{msec}$ ) (cue position $\times$ target position interaction). Table 13 and Figure 9 show that, with left-side cues, a cued-box advantage (facilitation) was manifest at all three SOAs $(+11,+9$, and $+10 \mathrm{msec})$-that is, for the left (cued), top, and right positions on the motion circle. In contrast, with right-side cues, there was facilitation only at the $100-\mathrm{msec}$ SOA, for the right (cued) position $(10 \mathrm{msec}$ ). At the $500-$ and 800 -msec SOAs (i.e., for the bottom and left positions), there tended to be inhibition ( -5 and $-1 \mathrm{msec})$. This pattern is consistent with attentive tracking of the box moving from left to right.
The early facilitation for the cued position (at 100-msec SOAs) was more marked when the relationship between that position and response hand were corresponding than when it was crossed (16 vs. $7 \mathrm{msec}$; see Figure 9 and Table 13). A similar pattern was found by Possamaï (1991) with spatially uninformative cues (recall that the cues in Experiment 7 were uninformative).

Furthermore, the tendency to track the left-to-right moving box appeared stronger when the subjects responded with the right hand rather than the left hand (marginally significant response hand $\times$ cue position $\times$ target position $\times$ SOA interaction). In particular, at 500-msec SOAs, there was significant facilitation for the left-cued (left-toright moving) box in the top position only for right-hand, but not for left-hand, responses (14 vs. $4 \mathrm{msec}$ ). Nevertheless, even with left-hand responses at 500-msec SOAs, there was a nonsignificant advantage for the left-to-right

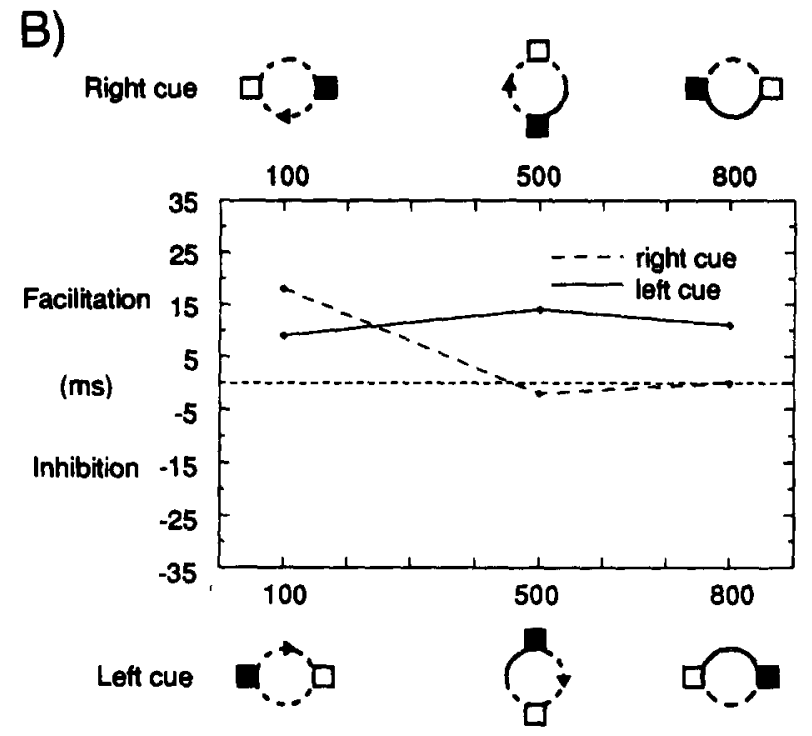

SOA (ms)

B)
A)

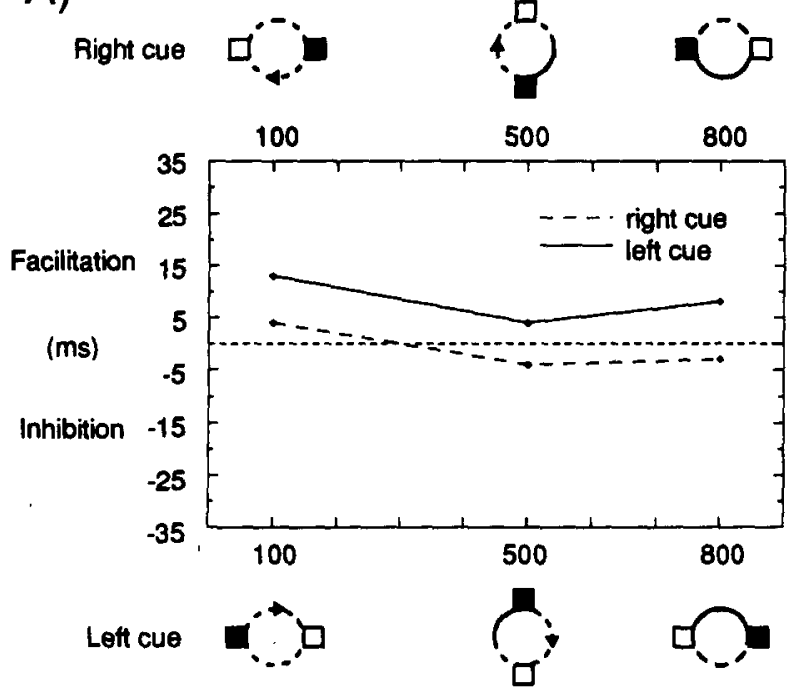

Figure 9. Mean reaction time facilitation/inhibition as a function of cue-target SOA, separately for left- and right-side cues with (A) left-hand responses and (B) right-hand responses. The icons along the $x$-axis indicate the positions of the cued (filled) and uncued (unfilled) boxes at the respective SOA. 
Table 14

Summary of Reaction Time Analysis of Variance Effects in Experiment 7

\begin{tabular}{lrlrl}
\hline \multicolumn{1}{c}{ Effect } & $F$ & $d f$ & $M S_{\mathrm{e}}$ & \multicolumn{1}{c}{$p$} \\
\hline Main Effects & & & & \\
TP & 12.46 & 1,9 & 166.19 & .01 \\
SOA & 243.40 & 2,18 & $2,524.22$ & .001 \\
Interactions & & & & \\
CP $\times$ TP & 5.17 & 1,9 & 166.80 & .05 \\
RH $\times$ TP & 4.84 & 1,9 & 61.42 & .075 \\
RH $\times$ CP $\times$ SOA & 3.56 & 2,18 & 82.12 & .05 \\
RH $\times$ CP $\times$ TP $\times$ SOA & 3.02 & 2,18 & 88.28 & .075 \\
\hline
\end{tabular}

Note- $\mathrm{RH}=$ response hand $\mathrm{CP}=$ cued position; $\mathrm{TP}=$ target position; SOA $=$ stimulus onset asynchrony.

moving box in the top position, both with left-side and right-side cues (4-msec advantage in both cases).

Errors. Anticipation and catch-trial errors were rare overall (less than $1 \%$ on average, with no subject above $2 \%$ ). An ANOVA of the arcsine-transformed anticipation rates, with the factors experiment, cue position, target position, and SOA, failed to reveal any significant effects. However, anticipations tended to be made only at the 800msec SOAs.

\section{Discussion}

Experiments 7A and 7B showed no evidence of dynamic, object-centered IOR; rather, the data were consistent with attentive tracking of the box that moved from left to right. Experiments 7A and 7B differed from the previous experiments in that the box motion started at the same time as the central flash occurred, $200 \mathrm{msec}$ after peripheral cue onset. Experiments 7A and 7B differed from each other in whether or not a target could be presented before the central flash/box motion onset. The fact that no dynamic, object-centerd IOR was observed in Experiments $7 \mathrm{~A}$ or $7 \mathrm{~B}$ argues that these variables are not crucial for the effect to occur.

Instead of dynamic, object-centred IOR, evidence of attentive left-to-right tracking was found in Experiment 7. However, the fact that the evidence was less strong than that found in Experiments 2, 3, and 4 in which the central flash occurred $500 \mathrm{msec}$ after peripheral cue onset-suggests that the early onset of the central flash in Experiment 7 interfered with attentive tracking (see also Experiment 6).

Furthermore, Experiment 7 showed evidence of a response-hand effect on attentive tracking. The left-to-right tracking preference appeared more marked when the right hand was used to make a simple keypress response to the target. This points toward the influence of a dynamic stimulus- response compatibility effect in producing simple manual reactions to moving objects. Assuming that even a simple manual response involves (at least rudimentary) preparation of a directed movement to interact with the target, the use of the right hand would be more appropriate for an object moving from the left to the right (on a circular trajectory). Therefore, the use of the right hand might produce a response bias to, and/or promote attentive tracking of, the left-to-right moving box. However, the fact that some (nonsignificant) advantage was also evident with left-hand responses suggests that other factors contribute to determine the preferred tracking direction-in particular, overlearned left-to-right scanning in reading. (These suggestions concerning the role of response hand in left-to-right attentive tracking should be viewed as tentative, since the relevant interaction was only marginally significant.)

\section{GENERAL DISCUSSION}

\section{IOR in Static Displays}

In Experiments 1, 2, and 5 (with the latter being the control condition for Experiments 3, 4, and 6), patterns of early facilitation and later inhibition (IOR) were found under the stationary conditions. This means that the present experimental conditions were conducive to the manifestation of the standard (environmental) IOR effect. All experiments taken together, the early facilitation (100-msec SOA) showed no difference between left- and right-side cues (12 vs. $13 \mathrm{msec}$ ) (facilitation/inhibition combined across experiments). However, IOR (1,300-msec SOA) was larger with left-side cues than with right-side cues $(-21$ vs. $-12 \mathrm{msec}$ ). Experiment 5 provided evidence pointing to the role of the response hand in producing this asymmetry. IOR tended to be greater when the relationship between response hand and cue position was crossed than when it was corresponding ( -23 vs. $-12 \mathrm{msec}$ ).

Considered together with the experiment of Possamaï (1991), the present experiments show that the pattern of early facilitation and later IOR for cued locations cannot be adequately explained without recourse to response mechanisms. Furthermore, a purely response-based account of these effects is possible in principle (see Discussion of Experiment 5). However, there is evidence from other studies that the early facilitation involves a perceptual component--that is, enhanced detectability of targets (even of simple luminance increments) at cued locations (e.g., Downing, 1988; Müller \& Humphreys, 1991). In the present experiments, perceptual facilitation may have added to the motor priming of simple manual responses to such targets. In contrast, there is little evidence of later IOR effect involving perceptual inhibition. Several studies have reported failure to find any IOR in choice RT tasks requiring target/nontarget discrimination (form discrimination, Egly, Rafal, \& Henik, 1992, and Terry, Valdes, \& Neill, 1994; color discrimination, Kingstone \& Gazzaniga, 1992; size discrimination, Pontefract \& Klein, 1988 [reported in Klein \& Taylor, 1994]) or in tasks requiring judgments of the temporal order in which stimuli appeared at cued and uncued locations (e.g., Maylor, 1985; but see Gibson \& Egeth, 1994a) ${ }^{8}$ An IOR effect on choice RTs has been observed only in tasks requiring a saccadic or manual localization response (e.g., Gibson \& Egeth, 1994a; Maylor, 1985).

In the light of these studies, the results of Experiment 5 would best fit with a response-based account of the IOR effect. Such an account has recently been suggested by Klein and Taylor (1994): "IOR is a reluctance to respond to an event at the inhibited location." The effect is coded 
in some response-relevant "map of spatial locations" (i.e., "motor representations used to locate objects in space"), distinct from visual representations subserving, for example, form, color, and size discrimination (which are not subject to IOR). Klein and Taylor's account makes the assumption that, "normally, detection responses [e.g., simple RT task] are implicitly 'to a spatial location." ' IOR arises due to a "criterion shift ... for 'responses to' stimuli from a particular location."

\section{IOR in Dynamic Displays}

While the present experiments replicated the standard (environmental) IOR effect (see Posner \& Cohen, 1984), they failed to provide any evidence of dynamic, objectcentered IOR (see Tipper et al., 1991, Tipper et al., 1994) in any of the moving conditions. Experiments 3, 4, 6A, and 7 showed that the failure to replicate the effect cannot be attributed to different types of object motion used by Tipper et al. and in (some of) the present experiments, different object eccentricities, different SOAs between peripheral cue and central flash, asynchrony of the box motion and central flash onset, or presentation of targets before these events.

However, all moving experiments consistently produced evidence of attentive tracking of the object that moved from left to right, no matter whether in clockwise or counterclockwise direction. Attentive tracking of left-to-right moving objects was in evidence even with valid right-side cues (Experiments 2, 3, and 4). That is, within 150$300 \mathrm{msec}$ after the cue, the uncued (left-to-right moving) box was tracked despite the fact that the target was four times more likely to appear in the cued (right-to-left moving) box prior to the central flash (500-msec SOA). In other words, the tracking tendency proved stronger than any attempts to allocate attention in accordance with the known signal probabilities. Furthermore, attentive tracking was not (or at least not completely) interrupted by the central flash, regardless of whether the flash was presented 500 msec (Experiments 1, 2, 3, and 4) or $200 \mathrm{msec}$ (Experiments 6 and 7) after cue onset.

The only pattern in any way suggestive of dynamic, object-centered IOR was observed in Experiment 6B. With left-side cues at the 400-msec SOA, RTs to cued-box targets in the upper position tended to be slower than RTs to uncued-box targets in the lower position despite attentive tracking of the cued box (as evidenced in Experiment 6A). However, this effect is unlikely to reflect dynamic, object-centered IOR because there also tended to be a disadvantage for the upper position relative to the lower position with right-side cues (i.e., the uncued-box target in the upper position tended to be inhibited). The most plausible explanation for this pattern is provided by attentive tracking of the upper (left-to-right moving) box, with attention overshooting that box due to the box motion being unpredictably disrupted by the target presentation.

Interestingly, Tipper et al. (1994), in their Experiments $1-3$, found no RT difference between the cued and uncued boxes after a $180^{\circ}$ rotation (in contrast to Experiments 2 and 3 of Tipper et al., 1991, which showed no evidence of re- duced dynamic, object-centered IOR after semicircular rotations). This would agree with the present Experiment 6, where the absence of any such effect was attributed to the box motion having come to a predictable halt. However, Tipper et al. (1994) argued that, with a $180^{\circ}$ rotation, IOR to the environmental location of the cue (e.g., left) is counterbalanced by object-centered IOR to the cued box (right), the assumption being that environmental IOR and dynamic, object-centered IOR are separable components of the IOR effect (see their Experiments 4 and 5).

By contrast, the moving conditions of the present experiments produced little evidence of either dynamic, object-centered IOR (as already discussed) or environmental IOR. For example, consider the facilitation/inhibition for the 700/800-msec SOAs, when the boxes had rotated by $180^{\circ}$, and the $1,300-\mathrm{msec}$ SOA, after they had rotated by $360^{\circ} .{ }^{9} \mathrm{After} 180^{\circ}$ rotations, a cued box that had been at the left position at the time of the cue (left-cued box) had moved into the right position, and a cued box that had been at the right position at the time of the cue (right-cued box) had moved into the left position. RTs to targets in the left-cued box occupying the right position (after $180^{\circ}$ rotation) showed facilitation ( $8 \mathrm{msec}$ ), whereas RTs to targets in the right-cued box occupying the left position showed inhibition $(-9 \mathrm{msec})$. After $360^{\circ}$ rotations, a leftcued box had moved back into the left position and a rightcued box had moved back into the right position. RTs to targets in the left-cued box on the left showed inhibition $(-11 \mathrm{msec})$, whereas RTs to targets in the right-cued box on the right tended to show facilitation $(+4 \mathrm{msec})$.

Any attempt to account for this pattern in terms of antagonistic environmental and object-centered IOR (see Tipper et al., 1994) would lead to contradictions. At $180^{\circ}$ rotation, IOR to the environmental location of the cue would be inferred to outweigh object-centered IOR to the cued box with left-side cues, and vice versa with right-side cues. A similar problem arises at $360^{\circ}$ rotation where the environmental and dynamic, object-centered components of IOR should add to each other (because the cued box has returned to the environmental position of the cue) (see Tipper et al., 1991). However, only the left box exhibited inhibition, the right (if anything) exhibited facilitation, and the inhibition was equivalent to that at $180^{\circ}$ rotation. The most parsimonious account of these data is provided by a preference for targets (that move from the left) to the right.

Furthermore, note that, at the $1,300-\mathrm{msec}$ SOA, inhibition for cued boxes in the left position was $-21 \mathrm{msec}$ in the stationary conditions and $-11 \mathrm{msec}$ in the moving conditions (after $360^{\circ}$ rotation); similarly, inhibition for cued boxes in the right position was $-12 \mathrm{msec}$ in the stationary conditions but $+4 \mathrm{msec}$ (i.e., inhibition was absent) in the moving conditions. This pattern of (approximately additive) effects suggests that no environmental IOR was operating in the moving conditions, only a 10 - to 16-msec preference for right-side targets (stationary condition) or left-to-right moving targets (moving condition).

Perhaps the box motion prevents environmental IOR from becoming manifest under the moving condition. Motion is achieved by rapid (apparent-motion-type) displace- 
ments of the peripheral boxes, which are thought to act analogously to peripheral (onset) cues (e.g., Folk, Remington, \& Wright, 1994). For example, the displacements might place attentional priority tags on the changing box positions (e.g., Yantis \& Johnson, 1990; Yantis \& Jones, 1991), canceling any inhibitory tags placed by the cue. (One could object that there are two simultaneous displacements [i.e., two moving boxes]. But there is evidence that multiple locations can be tagged simultaneously.) For the same reason, the flash in the display center may not be sufficient to hold attention in the center (because priority tags continue to be placed in the periphery).

\section{Dynamic, Object-Centered IOR and Attentive Tracking}

Although the present experiments did not produce any evidence of dynamic, object-centered IOR, they do not rule out its existence. Later experiments by Tipper et al. (1994; reviewed earlier in this paper) replicated the effect under conditions more varied than those used in the Tipper et al. (1991) study and in the present study (see also Abrams \& Dobkin, 1994). ${ }^{10}$

Perhaps, dynamic, object-centered IOR may be observed only under conditions that effectively prevent attentive tracking. It is possible that Tipper and his colleagues were more successful in doing so than we were in the present experiments. There may be several reasons for this. The first is that their experiments (with one exception) used rotations of $180^{\circ}$ or less (see also Abrams \& Dobkin, 1994, who required a saccadic response to the target presented in a box that had rotated $90^{\circ}$ ) versus rotations of $360^{\circ}$ in the present Experiments 1, 2, 3, 4, and 7. Perhaps, attentive tracking becomes an established strategy only with larger than semicircular rotations. Some evidence for this may be provided by the present Experiment $6 \mathrm{~A}$, which used $180^{\circ}$ rotations and in which tracking appeared reduced (though not completely abolished). However, Experiment 3 of Tipper et al. (1991) would seem to argue against this possibility. In that experiment, they used a $270^{\circ}$ rotation and still observed dynamic, object-centered IOR. A second reason might be found in the fact that, in some of their later experiments, Tipper et al. (1994) presented multiple (i.e., more than two) objects of different colors and, probably, different luminances. In other words, there were various competing stimulus attributes by which an object could be selected for tracking (luminance, color, motion). This could have prevented consistent attentive tracking.

Another possibility is that dynamic, object-centered IOR is observed early during subjects' performance on the task but is then replaced by attentive tracking. Assuming that "[object-centered IOR] mechanisms are used sparingly" (perhaps because they are demanding), "inhibition [may be] abandoned when other strategies can be developed" (S. P. Tipper, personal communication, May 6, 1995). Thus, dynamic, object-centered IOR would be manifest in the experiments of Tipper and colleagues that often had no more than 150 trials, but not, or only initially, in the present experiments (which consisted of several thousand trials in total). To test whether dynamic, object-centered IOR was evident early on in the present experiments, the data were reanalyzed, comparing task performance between the first and second halves of each experiment. These analyses failed to reveal any evidence of a (strategic) change in task performance with practice. However, since the subjects were familiarized with the task in a session of unrecorded practice trials (on the day preceding the actual experiment), any change in task performance could have occurred prior to the recorded trials. More controlled studies of practice effects are therefore in order. Tipper and colleagues, who are currently conducting such a study, have preliminary evidence that dynamic, object-centered IOR (and environmental IOR) does indeed disappear during the course of practice (S. P. Tipper, personal communication, May 6, 1995). Furthermore, work in our laboratory (using a paradigm kindly supplied to us by Tipper and colleagues) suggests that subjects experienced with visual detection experiments, but not necessarily IOR experiments, do not show dynamic, object-centered IOR (not even during the first 150 trials), in contrast to inexperienced subjects who show evidence of the effect. If confirmed, practice effects such as these would argue that object-centered IOR in dynamic displays is strategic (i.e., nonautomatic) in nature, perhaps involving the development of object attributions. This is in contrast to the cuing effects in static displays and attentive tracking in dynamic displays, which, in the present experiments, proved to be robust across many thousands of trials - suggesting that the underlying mechanisms are invoked automatically.

Even if one disregards the possibility that dynamic, object-centered IOR may be observed only early during practice, the effect (when observed) may be rather small (e.g., $-6 \mathrm{msec}$ in Experiment 6 of Tipper et al., 1994). This raises the question as to the functional importance of dynamic, object-centered IOR in the scanning of scenes containing moving objects, especially since dynamic scenes are likely to invoke attentive tracking. Note that attentive tracking may play an important role for maintaining the spatiotemporal continuity of object representations - in particular, "in resolving correspondence in apparent motion displays, where one set of items is replaced with a second set" (Cavanagh, 1993, p. 178), or in real-life scenes where a moving object is briefly occluded, wholly or in part, by other stimuli closer to the observer (see also Yantis \& Gibson, 1994).

The present experiments provided consistent evidence of attentive tracking but could offer only some tentative suggestions as to why there should be a tracking preference for objects moving from left to right. The source of this preference is likely to be found in the overlearned scanning direction in reading. But there also appears to be an effect of the response hand modifying this directional preference: Left-to-right scanning appeared more marked with right-hand responses (but was still evident with lefthand responses; Experiment 7). This points to the existence of a dynamic stimulus-response compatibility effect that is different from the Simon-type effect in static displays. In static displays, there is a bias toward objects on the same side as the response hand, which show enhanced fa- 
cilitation (at least with uninformative cues) and reduced IOR (Possamaï, 1991; Experiment 5). In contrast, in dynamic displays, there tends to be a bias toward objects that approach the response hand from the contralateral direction (Experiment 7), perhaps because that hand is best suited to interact with (intercept or grasp) the approaching object. Further work is necessary to confirm and clarify the nature of this dynamic tracking preference. In current experiments (Müller \& von Mühlenen, 1995), we ask whether a reversed, but hand-dependent, tracking preference is found in readers of languages written from right to left, ${ }^{11}$ whether the tracking preference generalizes to types of object motion other than the rotation used in the present experiments (e.g., linear motion), and whether the tracking preference is dependent on displays containing two objects (rather than just one) that move in opposite directions.

\section{Conclusion}

Human responses to objects in the visual environment are modulated by powerful spatial-attentional biases, such as preferences for objects in certain regions of the field and/or dynamic preferences for objects that move in certain directions. The right-side bias, and the tendency to track stimuli that move from left to right, may be explained in terms of overlearned scanning direction, but constraints arising from the response system also are likely to play a role (e.g., objects to the right, and moving from left to right, naturally attracting a right-hand response). One further bias is the tendency not to reattend to an object that attracted a stimulus-driven orienting response (the IOR effect). However, the present experiments cast doubt on the generality, if not the functional significance, of dynamic, object-centered IOR, which is supposed to move with the previously attended object. It appears that dynamic, objectcentered IOR is observed only under some special experimental conditions, and only early during (inexperienced) subjects' performance on the task.

\section{REFERENCES}

Abrams, R. A., \& Dobkin, R. S. (1994). Inhibition of return: Effects of attentional cuing on eye movement latencies. Journal of Experimental Psychology: Human Perception \& Performance, 20, 467-477.

BradDick, O. (1974). A short-range process in apparent motion. Vision Research, 14, 519-527.

CAstiello, U., \& Umiltì, C. (1992). Splitting focal attention. Journal of Experimental Psychology: Human Perception \& Performance, 18, 837-848.

Cavanagh, P. (1992, September 11). Attention-based motion perception. Science, 257, 1563-1565.

Cavanagh, P. (1993). The perception of form and motion. Current Biology, 3, 177-182.

CAVE, K. R., \& WolFE, J. M. (1990). Modeling the role of parallel processing in visual search. Cognitive Psychology, 22, 225-271.

CRAWFORD, T. J., \& MülLER, H. J. (1992). Spatial and temporal effects of spatial attention on human saccadic eye movements. Vision Research, 32, 293-304.

Dick, M., Ullman, S., \& SaGi, D. (1987, July 24). Parallel and serial processes in motion detection. Science, 237, 400-402.

DownING, C. J. (1988). Expectancy and visual-spatial attention: Effects on perceptual quality. Journal of Experimental Psychology: Human Perception \& Performance, 14, 188-202.
Duncan, J., \& Humphreys, G. W. (1989). Visual search and stimulus similarity. Psychological Review, 96, 433-458.

Egly, R., Rafal, R. D., \& HeNIK, A. (1992, November). Reflexive and voluntary orienting in detection and discrimination tasks. Poster presented at the annual meeting of the Psychonomic Society, St. Louis, MO.

FINLEY, G. A. (1985). A high-speed point plotter for vision research. Vision Research, 25, 1993-1997.

Folk, C. L., Remington, R. W., \& WRight, J. H. (1994). The structure of attentional control: Contingent attentional capture by apparent motion, abrupt onset, and color. Journal of Experimental Psychology: Human Perception \& Performance, 20, 317-329.

GaWryszewski, L. G., Riggio, L., Rizzolatti, G., \& Umiltà, C. (1987). Movements of attention in the three spatial dimensions and the meaning of "neutral" cues. Neuropsychologia, 25, 19-29.

GibSON, B. S., \& EgETH, H. (1994a). Inhibition and disinhibition of return: Evidence from temporal order judgments. Perception \& Psychophysics, 56, 669-680.

Gibson, B. S., \& EGETH, H. (1994b). Inhibition of return to objectbased and environment-based locations. Perception \& Psychophysics, 55, 323-339.

Halligan, P. W., \& Marshall, J. C. (1989). Laterality of motor response in visuo-spatial neglect: A case study. Neuropsychologia, 27, 1301-1307.

HEYwood, S., \& ChURCHER, J. (1980). Structure of the visual array and saccadic latency: Implications for oculomotor control. Quarterly Journal of Experimental Psychology, 32, 335-341.

Hodgson, T. L., \& MülleR, H. J. (1995). Evidence relating to premotor theories of attention. In J. M. Findlay, R. W. Kentridge, \& R. Walker (Eds.), Eye movement research: Mechanisms, processes, and applications (pp. 305-316). Amsterdam: North-Holland.

Hodgson, T. L., Müller, H. J., \& O'Leary, M. J. (1995). Attentional localization prior to simple and directed manual responses. Manuscript submitted for publication.

Honda, H., \& Findlay, J. M. (1992). Saccades to targets in threedimensional space: Dependence of saccadic latency on target location. Perception \& Psychophysics, 52, 167-174.

HuMPHREYS, G. W., \& Müller, H. J. (1993). SEarch via Recursive Rejection (SERR): A connectionist model of visual search. Cognitive Psychology, 25, 43-110.

IVRY, R. B., \& COHEN, A. (1990). Dissociation of short- and long-range apparent motion in visual search. Journal of Experimental Psychology: Human Perception \& Performance, 16, 317-331.

Joanette, Y., Brouchon, M., Gauthier, L., \& SAmson, M. (1986). Pointing with left versus right hand in left visual field neglect. Neuropsychologia, 24, 391-396.

JONIDES, J., \& YANTIS, S. (1988). Uniqueness of abrupt visual onset in capturing attention. Perception \& Psychophysics, 43, 346-354.

Kahneman, D., Treisman, A., \& GibBs, B. J. (1992). The reviewing of object files: Object-specific integration of information. Cognitive Psychology, 24, 175-219.

Kingstone, A., \& Gazzaniga, M. S. (1992, June). Covert orienting in the split brain. Paper presented at the meeting of the Canadian Society of Brain, Behaviour, and Cognitive Science, Quebec.

KLEIN, R. (1988). Inhibitory tagging system facilitates visual search. Nature, 334, 430-431.

KLEIN, R. M., \& TAYLOR, T. L. (1994). Categories of cognitive inhibition with reference to attention. In D. Dagenbach \& T. Carr (Eds.), Inhibitory mechanisms in attention, memory, and language (pp. 113150). San Diego, CA: Academic Press.

MAYLOR, E. A. (1985). Facilitatory and inhibitory components of orienting in visual space. In M. I. Posner \& O. S. M. Marin (Eds.), Attention and performance $X I$ (pp. 189-204). Hillsdale, NJ: Erlbaum.

MAYLOR, E. A., \& HockeY, R. (1985). Inhibitory component of externally controlled covert orienting in visual space. Journal of Experimental Psychology: Human Perception \& Performance, 11, 777-787.

MCCONKIE, G. W., \& RAYNER, K. (1976). Asymmetry of the perceptual span in reading. Bulletin of the Psychonomic Society, 8, 365-368.

MǘLLER, H. J. (1995). Reflexive and voluntary orienting of visual attention: Discrete or continuous interaction? Unpublished manuscript 
MÜLLER, H. J., \& HUMPHREYS, G. W. (1991). Luminance-increment detection: Capacity-limited or not? Journal of Experimental Psychology: Human Perception \& Performance, 17, 107-124.

Müller, H. J., \& von Mühlenen, A. (1995). Attentional tracking of moving objects. Manuscript in preparation.

OLDFIELD, R. C. (1971). The assessment of analysis of handedness: The Edinburgh Inventory. Neuropsychologia, 9, 97-113.

Pollatsek, A., Bolozky, S., Well, A. D., \& Rayner, K. (1981). Asymmetries in the perceptual span for Israeli readers. Brain \& Language, 14, 174-180.

POSNER, M. I. (1978). Chronometric explorations of mind. Hillsdale, NJ: Erlbaum.

Posner, M. I., \& Cohen, Y. A. (1984). Components of visual orienting. In H. Bouma \& D. G. Bouwhuis (Eds.), Attention and performance $X$ (pp. 531-556). Hillsdale, NJ: Erlbaum.

Posner, M. I., RaFal, R. D., Choate, L., \& Vaughan, J. (1985). Inhibition of return: Neural basis and function. Cognitive Neuropsychology, 2, 211:218.

Possamaï, C.-A. (1991). A responding hand effect in a simple-RT precueing experiment: Evidence for a late locus of facilitation. Acta Psychologica, 77, 47-63.

Previc, F. H. (1990). Functional specialization in the lower and upper visual fields in humans: Its ecological origins and neurophysiological implications. Behavioral \& Brain Sciences, 13, 519-575.

Pylyshyn, Z. W., \& STORM, R. W. (1988). Tracking multiple independent targets: Evidence for a parallel tracking mechanism. Spatial $V_{i-}$ sion, 3, 151-224.

Rafal, R. D., Calabresi, P. A., Brennan, C. W., \& Sciolto, T. K. (1989). Saccade preparation inhibits reorienting to recently attended locations. Journal of Experimental Psychology: Human Perception \& Performance, 15, 673-685.

RAYNER, K., \& BerTera, J. H. (1979, October 26). Reading without a fovea. Science, 206, 468-469.

Rizzolatti, G., \& Gallese, V. (1988). Mechanisms and theories of spatial neglect. In F. Boller \& J. Grafman (Eds.), Handbook of neuropsychology (Vol. 1, pp. 223-246). Amsterdam: Elsevier.

Rizzolatti, G., Riggio, L., Dascola, I., \& Umiltà, C. (1987). Reorienting attention across the horizontal and vertical meridians: Evidence in favour of a premotor theory of attention. Neuropsychologia, 25, 31-40.

RoBERTSON, I. H., \& NORTH, N. (1993). Active and passive activation of left limbs: Influence on visual and sensory neglect. Neuropsychologia, 31, 193-300.

SCHMIDT, W., KleiN, R. M., \& Müller, H. J. (1995). Temporal order judgments do not reveal "inhibition of return": A commentary on Gibson and Egeth (1994). Manuscript submitted for publication.

SHEPHERD, M. (1984). EMDISP: A visual display system with digital and analogue sampling. Behavior Research Methods, Instruments, \& Computers, 16, 297-302.

SimON, J. R., SLY, P. E., \& VilaPaKKaM, S. (1981). Effect of compatibility of S-R mapping on reactions towards the stimulus source. Acta Psychologica, 47, 63-81

Terry, K. M., VAldes, L. A., \& NeILl, W. T. (1994). Does "inhibition of return" occur in discrimination tasks? Perception \& Psychophysics, $55,279-286$

TiPPER, S. P., Driver, J., \& Weaver, B. (1991). Object-centred inhibition of return of visual attention. Quarterly Journal of Experimental Psychology, 43A, 289-298.

Tipper, S. P., Weaver, B., Jerreat, L. M., \& Burak, A. L. (1994). Objectbased and environment-based inhibition of return of visual attention. Journal of Experimental Psychology: Human Perception \& Performance, 20, 478-499.

Treisman, A. M. (1988). Features and objects: The Fourteenth Bartlett Memorial Lecture. Quarterly Journal of Experimental Psychology, 40A, 201-237.

Treisman, A. M., \& Gelade, G. (1980). A feature-integration theory of attention. Cognitive Psychology, 12, 97-136.

YANTIS, S. (1992). Multi-element visual tracking: Attention and perceptual organization. Cognitive Psychology, 24, 295-340.

YaNTIS, S. (1993). Stimulus-driven attentional capture. Current Directions in Psychological Science, 2, 156-161.

YANTIS, S., \& GiBSON, B. S. (1994). Object continuity in apparent mo- tion and attention. Canadian Journal of Experimental Psychology, 48 182-204.

YANTIS, S., \& JoHnson, D. N. (1990). Mechanisms of attentional priority. Journal of Experimental Psychology: Human Perception \& Performance, 24, 295-340.

YANTIS, S., \& JONES, E. (1991). Mechanisms of attentional selection: Temporally modulated priority tags. Perception \& Psychophysics, $\mathbf{5 0}$, 166-178.

YANTIS, S., \& JonidES, J. (1984). Abrupt visual onsets and selective attention: Evidence from visual search. Journal of Experimental Psychology: Human Perception \& Performance, 10, 601-621.

\section{NOTES}

1. The only attempt not to make the parallel/serial distinction is Duncan and Humphreys's (1989) "similarity theory." However, ultimately, even similarity theory has to admit the need for some spatially serial scanning mechanisms (see Humphreys \& Müller, 1993).

2. Henceforth, facilitation (an RT advantage for cued over uncued objects/positions) will be denoted by a positive sign; inhibition (an RT disadvantage for cued relative to uncued objects/positions) will be denoted by a negative sign.

3. Gibson and Egeth (1994b) have recently described another type of object-centered IOR that is different from the dynamic, object-centered IOR effect (i.e., IOR moving with whole-object ["global"] displacements) reported by Tipper et al. (1991). Gibson and Egeth found that IOR also accrues to points on the surfaces of a line drawing of a volumetric object (e.g., a brick) that change environmental position in a depth rotation of the object. They concluded that (one component of) IOR is associated with locations (surfaces) that are fixed with respect to an object rather than the environment.

4. In fact, the present Experiments 1-6 were carried out before the publication of the studies of Tipper et al. (1994) and Abrams and Dobkin (1994).

5. In contrast, the saccadic eye movement system prefers targets in the upper visual field (e.g., Heywood \& Churcher, 1980; Honda \& Findlay, 1992). See Previc (1990) for a review of visual field effects.

6. Data estimated from Figure 1 of Possamaï (1991).

7. According to S. P. Tipper (personal communication, October 4, 1994), "the target presented after only $100 \mathrm{msec}$ may have affected whether object-based IOR was engaged."

8. Gibson and Egeth (1994a) have recently reported IOR in a temporal order judgment (TOJ) task in which subjects had to indicate the location of the target presented first (left/right-hand choice RT task). Their account assumes that facilitation from the cue persists at long cue-target SOAs but is typically masked by the more dominant IOR effect. However, IOR may be released by a second stimulus (at another task-relevant location) presented after the cue but before the target at the cued location (i.e., there is relatively fast-acting "disinhibition of return" [DOR]), which would allow any remaining facilitation to become manifest. Note that Gibson and Egeth found evidence of IOR only with reference to a neutral (central cue) condition, but not in terms of an RT disadvantage in responding to the first target at the cued location relative to the first target at the uncued location. Gibson and Egeth argued that such a disadvantage was hard to observe in the TOJ task because DOR facilitated the processing of a target at the cued location. According to Gibson and Egeth, facilitation "expands" the temporal interval between the two targets when the first target appears at the cued location (and the second at the uncued location), or it "compresses" the interval when the second target appears at the cued location (and the first at the uncued location). Consequently, in the latter condition, responding to the first target at the uncued location at longer SOAs would be slowed because that target would, within $50-100 \mathrm{msec}$, produce DOR to the second target at the cued location, making the task harder by compressing the temporal interval to be resolved. Gibson and Egeth thus prefer a perceptual account of IOR in the TOJ task, though they concede that a response-based account could go some way in explaining their findings. Furthermore, their crucial argument against a response-based account of IOR (see Gibson \& Egeth, 1994a, p. 677) is debatable (Schmidt, Klein, \& Müller, 1995).

9. The values reported in the example are the facilitation/inhibition combined across the relevant experiments: Experiments 2, 3, 4, 6, and 7 
for $180^{\circ}$ rotations (700/800-msec SOAs), and Experiments 2, 3, and 4 for $360^{\circ}$ rotations $(1,300-\mathrm{msec} S O A s)$.

10. The existence of dynamic, object-centered IOR would not be at variance with the suggestion made above that the standard (environmental) IOR effect reflects response inhibition (see Klein \& Taylor, 1994). Instead of affecting a response-relevant representation of stimulus location, dynamic, object-centered IOR might influence a different representation, such as the "object-file" system of Kahneman et al. (1992). In other words, environmental and dynamic, object-centered IOR may indeed be dissociable (see Abrams \& Dobkin, 1994; Tipper et al., 1994). For example, Abrams and Dobkin found that, after a quartercircle movement of a peripherally cued box, the latency of saccadic eye movements to that box showed evidence of IOR only if the imperative signal for making the saccade occurred inside the cued box (not if it occurred in the display center). From this, Abrams and Dobkin argued that some stimulus coding stage is affected by dynamic, object-centered IOR, but not the eye movement as such. But see Klein and Taylor (1994) for an attempt at a response-inhibition account of dynamic, object-centered IOR.

11. We are grateful to $A$. Kramer for suggesting this experiment to us (A. Kramer, personal communication, October 4, 1994).

(Manuscript received July 25, 1994; revision accepted for publication July 23,1995 .) 